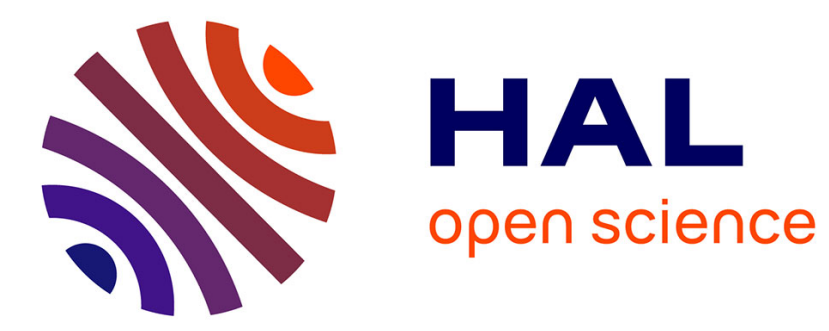

\title{
Indoor air quality and comfort in seven newly built, energy-efficient houses in France
}

Mickaël Derbez, Bruno Berthineau, Valérie Cochet, Murielle Lethrosne, Cécile Pignon, Jacques Riberon, Séverine Kirchner

\section{- To cite this version:}

Mickaël Derbez, Bruno Berthineau, Valérie Cochet, Murielle Lethrosne, Cécile Pignon, et al.. Indoor air quality and comfort in seven newly built, energy-efficient houses in France. Building and Environment, 2014, 72, p. 173-187. 10.1016/j.buildenv.2013.10.017 . hal-01102234

\section{HAL Id: hal-01102234 \\ https://hal-cstb.archives-ouvertes.fr/hal-01102234}

Submitted on 12 Jan 2015

HAL is a multi-disciplinary open access archive for the deposit and dissemination of scientific research documents, whether they are published or not. The documents may come from teaching and research institutions in France or abroad, or from public or private research centers.
L'archive ouverte pluridisciplinaire HAL, est destinée au dépôt et à la diffusion de documents scientifiques de niveau recherche, publiés ou non, émanant des établissements d'enseignement et de recherche français ou étrangers, des laboratoires publics ou privés. 
Indoor air quality and comfort in seven newly built, energy-efficient houses in France

DERBEZ Mickaël $1^{1}$ (corresponding author)

mickael.derbez@,cstb.fr

telephone : +3316468 8989, Fax : +33164688823

BERTHINEAU Bruno ${ }^{1}$

bruno.berthineau@cstb.fr

COCHET Valérie ${ }^{1}$

valerie.cochet@cstb.fr

LETHROSNE Murielle $^{1}$

PIGNON Cécile ${ }^{1}$

cecile.pignon@cstb.fr

RIBERON Jacques $^{1}$

jacques.riberon@cstb.fr

KIRCHNER Severine ${ }^{1}$

$\underline{\text { severine.kirchner@estb.fr }}$

${ }^{1}$ Université Paris-Est, Centre Scientifique et Technique du Bâtiment - Observatoire de la Qualité de 1'Air Intérieur - 84, avenue Jean Jaurès - Champs sur Marne - 77477 Marne la Vallée cedex 2 - FRANCE 


\section{Introduction}

Because of the global warming, many governments have taken action to reduce anthropogenic greenhouse-gas emissions, to promote energy efficiency and to support for renewable energy. In France, the residential and commercial building sector is responsible of $23 \%$ of national greenhouse-gas emissions and is the largest energy consumer, accounting for $43 \%$ of energy consumption in the country in 2007 [1]. In 2011, the average unit energy intensity of the residential sector was $190 \mathrm{kWh} / \mathrm{m}^{2}$, higher than that of the commercial sector [2]. In this context, France has pledged to reduce greenhouse-gas emissions by $75 \%$ by 2050 and to reduce building energy consumption by $38 \%$ by 2020 [3]. Existing structures are being refurbished to increase energy efficiency at an accelerating rate, and as of 2013, all newly constructed buildings must meet the French 2012 thermal-regulation standards (RT 2012) for buildings. Although these new airtight buildings must have a primary conventional-energy consumption not exceeding $50 \mathrm{kWh} / \mathrm{m}^{2}$ per year, there are no requirements directly protecting the health and wellbeing of occupants. Moreover, the only literature review on indoor air quality (IAQ) in highly energy-efficient houses [4] concludes that "with regard to indoor air quality, there is a dearth of information relating to highly efficient structures". The authors note that it is difficult to extrapolate the results of studies of the construction of airtight buildings in colder climates (Canada, Central Europe and northern USA) to other countries because of differences in climate, construction practices, indoor sources depending of what people purchase on their homes and the social and economic conditions of the occupants. Finally, a small number of studies have investigated indicators of IAQ $[5,6,7,8,9,10,11]$, but none has conducted an IAQ longitudinal survey and compare their results with those of standard buildings.

The objective of the present study, which was funded by the French Observatory of Indoor Air Quality (OQAI in French), is to evaluate the IAQ and the occupants' comfort in seven low-energy, newly built houses in France. The survey was conducted during the pre-occupancy stage and during occupancy in summer and winter. The concentrations of several IAQ indicators and the indoor environmental parameters were measured during occupation. These results were compared to the IAQ of standard 
French houses [12], to the results of previous studies conducted in new dwellings and to the IAQ guideline values currently used in France. The air changes per hour (ACH) from mechanical ventilation with heat recovery (MVHR) were measured and compared to those of standard French homes [13]. The air-exhaust rates were compared to the French standards [14] for minimal airflow for dwellings according to the number of habitable rooms. The noise levels were measured, and the occupants' perceptions were evaluated with a questionnaire.

\section{Materials and methods}

A recently developed method for assessing IAQ, occupant comfort and energy consumption was applied in this study. A detailed description of sampling and measurement techniques has been presented elsewhere [15]. A short overview of the analytical procedures and the sampling strategy is given below.

\subsection{Description of the seven single-family detached houses}

Seven newly built, single-family detached houses in four regions of France (Centre, Pays-de-la-Loire, Ilede-France and Rhône-Alpes) were investigated in this study (Table 1).

Table 1 - Main characteristics of the seven new single-family detached houses investigated in this study in terms of construction, equipment and occupancy

The buildings had one or two stories, and one had an attached garage (A). All houses were constructed in accordance with an energy-efficient building certification such as the French BBC-Effinergie certification or the German Passivhaus certification. Three houses were certified (A: BBC-Effinergie; C and D: Passivhaus); house B's certification process was on-going, and the builders or owners of the other houses are not pursuing certification. Houses F and G satisfied the requirements of all 14 targets of the French High Environmental Quality Programme (HQE). The airtightness of all buildings was measured with a 
blower-door test between 0.29 and $3.33 \mathrm{vol} / \mathrm{h}$ under 50 Pascal pressure $\left(0.06\right.$ and $0.41 \mathrm{~m} / \mathrm{h} \cdot \mathrm{m}^{2}$ under 4 Pascal pressure). The houses' annual consumption of conventional primary energy (heating, cooling, ventilation, auxiliaries, hot water production, lighting facilities) was between 46 and $79 \mathrm{kWh} / \mathrm{m}^{2} /$ year. These houses were well within the requirements of the French 2005 thermal regulations (RT 2005) for buildings (airtightness less than $0.8 \mathrm{~m} / \mathrm{h} \cdot \mathrm{m}^{2}$ under $4 \mathrm{~Pa}$ and annual consumption of conventional primary energy less than $150 \mathrm{kWh} / \mathrm{m}^{2} /$ year). The houses also qualified as highly energy-efficient houses as defined by the French 2012 thermal regulation (RT 2012) because of their high airtightness (under 0.6 $\mathrm{m}^{3} / \mathrm{h} \cdot \mathrm{m}^{2}$ under $4 \mathrm{~Pa}$ ) and their theoretical low energy consumption (an annual consumption of conventional primary energy equal or less than $50 \mathrm{kWh} / \mathrm{m}^{2} /$ year). All of the houses were wood frame except for house A (stone) and used mineral (A, F and G) or vegetable (B, C, D and E) insulating material. All of the houses were equipped with an MVHR system with two, three or four normal fan speeds and occasionally one boost setting. The heating systems were mostly heat pumps (A, C, D, F and G) or wood stoves (B and E). House D had a wood stove for enjoyment rather than function. Hot water was mainly provided by solar panels with electric boosters (B, C, D, F and G) except in two houses (thermodynamic in house A and electric in house E). All of the houses but A had products and materials described by the manufacturers as low volatile-organic-compound-emitting. The inhabitants were families of 2-4 non-smokers, except for house G, which remained unoccupied during this study. The occupation rates were often lower than the median occupation rate (0.8) of the standard French houses [13] suggesting that these houses were under-occupied or were larger than an average French home.

\subsection{Measurement protocol}

The IAQ and indoor environmental parameters was monitored between February 2009 and July 2010 (Figure 1) just after the houses' completion (except for house A, completed in March 2008) for less than one year each. The IAQ was monitored in the main bedroom and in the living room and kitchen 
(collectively called living room") for three weeks in each building in the pre-occupancy stage and during occupancy (summer: Sum; winter: Win) except in houses F and G. The ACH, the air exhaust rates and the level of noise were determined simultaneously in the pre-occupancy stage. The temperature, the relative humidity and the concentration of radon were measured only in occupied houses. The MVHR systems were switched on during these investigations at the medium normal fan speed during the pre-occupancy stage (except for houses E and G, where the MVHR systems were turned off) and in manual or automatic mode during occupancy.

Figure 1 - Weekly investigation and moving dates of the seven new single-family detached houses between February 2009 and July 2010

The strategy of sampling / measurement and the accuracy/uncertainty of the indoor air quality parameters are presented in Table 2 .

Table 2 - Strategy of sampling/measurement and accuracy of indoor air quality parameters

Every ten minutes during the investigation, total volatile organic compounds (TVOC in toluene equivalent in $\mu \mathrm{g} / \mathrm{m}^{3}$ ) were measured with a photoionisation detector (PID) (PGM 7240 - RAE Systems) in the living room and carbon dioxide $\left(\mathrm{CO}_{2}\right.$ in $\left.\mathrm{ppm}\right)$ was measured by a non-dispersive infra-red probe (TSI Q-Trak 8552) in the main bedroom. Individual volatile organic compounds (VOC) and aldehydes were collected over seven days in the main bedroom by a passive sampler (Radiello ${ }_{\text {, }}$, and Fondazione Salvatore Maugeri - IRCCS, Italy) with stainless steel net cartridges filled, respectively, with Carbograph 4 adsorbents and with 2,4-dinitrophenylhydrazine (2,4-DNPH)-coated Florisil. Sixteen VOC (1,2,4trimethylbenzene, 1,4-dichlorobenzene, 1-methoxy-2-propanol and its acetate, 2-butoxyethanol and its acetate, benzene, ethylbenzene, m-/p-xylenes, n-decane, n-undecane, o-xylene, styrene, tetrachloroethylene, toluene, trichloroethylene) and four aldehydes (acetaldehyde, acrolein, formaldehyde, hexaldehyde) were quantified in $\mu \mathrm{g} / \mathrm{m}^{3}$ by, respectively, gas chromatography, mass spectrometry and flame ionisation and high-performance liquid chromatography and detection by UV absorption. These 
compounds were measured during the national survey of IAQ in French dwellings [12], and the analytical method and the detection limit for each compound were previously detailed by [16]. Then, all other organic compounds whose concentrations exceeded $1 \mu \mathrm{g} / \mathrm{m}^{3}$ were identified and quantified in $\mu \mathrm{g} / \mathrm{m}^{3}$ toluene equivalent. Carbon monoxide ( $\mathrm{CO}$ in $\mathrm{ppm})$ was monitored only in winter every five minutes during seven days with an electrochemical sensor (Drager Pac III) in each room that contained combustion equipment. The mass concentration of suspended particulate matter with an aerodynamic diameter less than $2.5 \mu \mathrm{m}\left(\mathrm{PM}_{2.5}\right)$ was measured in the living room with a sampling system (Chempass, Model. 3400, Thermo Fisher Scientific) coupled to an air sampler (Microvol 1100, Ecotech) operating at $1.8 \mathrm{l} / \mathrm{min}$ from $5 \mathrm{pm}$ to 8 am on weekdays and for 24 hours a day on weekends. The filters (37-mmdiameter PTFE membrane, 2- $\mu \mathrm{m}$ porosity, Gelman Sciences) were weighed before and after sampling according to NF EN 14907 [17], and mass concentrations are given in $\mu \mathrm{g} / \mathrm{m}^{3}$. During both investigations during occupancy, room temperatures $\left(\mathrm{T}\right.$ in ${ }^{\circ} \mathrm{C}$ ) and relative humidity ( $\mathrm{RH}$ in \%) were monitored every ten minutes with Hydrolog sensors (Rotronic) in the main bedroom and the living room at different heights. Radon concentrations $\left(\mathrm{Bq} / \mathrm{m}^{3}\right)$ were measured over more than two months using two Kodalpha LR 115 detectors (Dosirad, and France), one in the living room and the other in the bedroom, after the inhabitants moved in. The radon measurement was made principally during fall months for houses A, C, E, during spring months for houses $\mathrm{D}$ and $\mathrm{F}$ and during fall/winter months for house B. During the preoccupancy stage and for normal fan speeds (low, medium, high and sometimes very high) of the MVHR, the $\mathrm{ACH}\left(\right.$ in $\left.^{-1}\right)$ in the main bedroom and living room, the air exhaust rate $(1 / \mathrm{s})$ and the mean noise level (in $\mathrm{dB}(\mathrm{A})$ ) were measured, respectively, by SF6 tracer gas (B \& K Multigas Monitor type 1302 with a B \& K multipoint sampler and doser type 1303), by an array of hot wires (Swemaflow 233, Admi Industries) and by a type-II sonometer (Centre 322). The ACH was measured under the same outdoor conditions. No ACH measurements were made under the MVHR boost fan speed, which was activated for only a short period. The average $\mathrm{ACH}$ of each building was estimated, taking into account the $\mathrm{ACH}$ measurements of both rooms, the volume of those rooms and the total volume of the house. Because doors were opened very often during our investigations and thus homogenous zone of concentration 
created, we supposed that air removal measured in 2 rooms could be translated to the air removal of the whole house. Because the MVHR systems are not very often checked during/after the completion of the building, we decided to evaluate its performance in terms of $\mathrm{ACH}$, air exhaust rate and noise level. Concurrent with sampling and measuring, survey questionnaires were developed based on the national survey on indoor air quality in French dwellings [18] to collect general information on newly constructed houses, their equipment, their occupancy and the activities and perceptions of the inhabitants during each investigation.

\subsection{Graphical representation and statistical analysis}

A histogram representation with vertical error bars was used for measurements of $\mathrm{T}, \mathrm{RH}, \mathrm{PM}_{2.5}$, radon, air exhaust rates and mean noise levels.

The software package SAS 9.1 was used for statistical analysis. To characterise the distribution of the raw data, the following parameters were calculated for the concentrations of $\mathrm{CO}_{2}$ and for the measurements of T and RH: minimum, arithmetic mean, median, maximum and $25^{\text {th }}$ and $75^{\text {th }}$ percentile. For VOC and aldehyde values below the limit of quantification (LQ), the calculated value of the LQ divided by two was used in the statistical calculation (arithmetic mean, median, geometric mean). The differences in indoor environmental parameters $\left(\mathrm{CO}_{2}, \mathrm{~T}\right.$ and $\left.\mathrm{HR}\right)$ between occupancy in summer and in winter for each house were assessed using the Kruskal Wallis rank-sum test. A two-sided test was used because the sign of the difference was not known a priori. Spearman's rank correlation $\left(\mathrm{r}_{\mathrm{s}}\right)$ was used to express correlations between the indoor $\mathrm{PM}_{2.5}$ levels and outdoor $\mathrm{PM}_{2.5}$ levels. P-values $<0.05$ were considered statistically significant.

\section{Results}

\subsection{Performance of MVHR}


The performance of MVHR was evaluated for six houses during the pre-occupancy stage after inspection and their adjustment by the installers; in houses D and E, the systems of ventilation were adjusted after measurement.

\subsubsection{Air exchange per hour (ACH)}

Table 3 presents the measurement of $\mathrm{ACH}\left(\mathrm{in}^{-1}\right.$ ) for the living room and the main bedroom and the average $\mathrm{ACH}$ for the house.

Table 3 - Measured ACH per room and estimation of average $\mathrm{ACH}\left(\mathrm{h}^{-1}\right)$ by house depending on the fan speed of the MVHR system in six houses (confidence interval). n.m.: not measured; n.e.: not estimated

When the MVHR systems were switched off, the ACH of both rooms induced by air leakage did not exceed $0.05 \mathrm{~h}^{-1}$, except in house F, where it reached $0.1 \mathrm{~h}^{-1}$. When the MVHR systems were turned on, the $\mathrm{ACH}$ values increased with increasing fan speed (in houses $\mathrm{A}, \mathrm{B}, \mathrm{D}$ and $\mathrm{F}$ ). The $\mathrm{ACH}$ values ranged between 0.4-0.8 $\mathrm{h}^{-1}$ in house A, 0.2-1.2 $\mathrm{h}^{-1}$ in house $\mathrm{B}, 0.1-1.3 \mathrm{~h}^{-1}$ in house $\mathrm{C}, 0.2-0.7 \mathrm{~h}^{-1}$ in house $\mathrm{D}, 0.2$ $0.6 \mathrm{~h}^{-1}$ in house E and 0.5-0.6 $\mathrm{h}^{-1}$ in house F. Shortcomings appeared at the highest fan speed, where ACH values were in some cases equal to the $\mathrm{ACH}$ value at the medium fan speed (house $\mathrm{C}$ ) or even lower (bedroom of house E). The average ACH values for MVHR systems without a boost fan speed were between 0.1 and $0.3 \mathrm{~h}^{-1}$ at the lower fan speed, 0.3 and $0.5 \mathrm{~h}^{-1}$ at the medium speed and up to $1 \mathrm{~h}^{-1}$ at the highest speed. For the MVHR systems with a boost fan speed (houses A and F), the minimum average $\mathrm{ACH}$ values were $0.6 \mathrm{~h}^{-1}$ and $0.5 \mathrm{~h}^{-1}$, respectively.

\subsubsection{Air exhaust rates}

Air exhaust rates $(1 / \mathrm{s})$ were measured for each outlet and for each fan speed of the MVHR system. For technical reasons (e.g., height, size, geometry of the outlets, presence of furniture fixed to the wall near the outlets), not all measurements were recorded. Figure 2 shows that the air exhaust rates increased with the increasing fan speed of the ventilation systems for the majority of houses, though deviations appear in 
houses A and F. The air exhaust rates were the same for the lower as for the medium fan speed in house A (WC and bathroom 1) and house F (WC and bathroom 2). Finally, for both houses and considering only WC and bathroom outlets, the difference in the air exhaust rates between the lower and the higher fan speeds was smaller (less than $1.7 \mathrm{l} / \mathrm{s}$ ) than in the other houses (between 3.3 and $8.6 \mathrm{l} / \mathrm{s}$ ).

Figure 2 - Measured air exhaust rate (1/s) per room by the fan speed of the MVHR system in six houses

\subsubsection{Average noise level}

The average noise level ( $\mathrm{dB}(\mathrm{A}))$ was measured for each MVHR fan speed. The results are presented in Figure 3, and all measured values less than or equal to $30 \mathrm{~dB}(\mathrm{~A})$ (under the range value of the sonometer used) were replaced by the symbol *. The average noise level increased with increasing MVHR fan speed, except in a few rooms in house F. The utility room where the MVHR system was located was the noisiest (value ranged between 33 and $59 \mathrm{~dB}(\mathrm{~A})$ ), except in house D. The bedrooms (and occasionally office rooms) were generally the quietest (less than 30 to $33 \mathrm{~dB}(\mathrm{~A})$ ), except in houses $\mathrm{B}$ and $\mathrm{D}$ (up to 48 and $36 \mathrm{~dB}(\mathrm{~A})$, respectively). The average noise levels in house E were markedly lower. Overall, indoor noise levels were rated between —qite pleasant" and — etremely pleasant" by the inhabitants. Noises coming from inside the house, especially those from the MVHR ventilator and those that were noticeable at bedtime (B), during the night (A, D) or during quiet parts of the day were rated as more bothersome than noises from outside.

Figure 3 - Measured average noise level (dB(A)) per room depending on the MVHR fan speed in six houses (* average noise level value $\leq 30 \mathrm{~dB}(\mathrm{~A})$ ) (BAT: bathroom; BED: bedroom; LR: living room; OFF: office room; UR: utility room)

\subsubsection{Use of the MVHR system}


During occupancy, several technical improvements were made to the MVHR systems in response to complaints from the inhabitants regarding the poor adjustment of the air-flow rate (houses A and E), disturbance of the air-flow rate during occupancy (houses A and C) or after cleaning the inlets/outlets (house B), noise disturbance (house A and C) and the need to replace components of the ventilation system (houses A and F). The inhabitants reported that the MVHR systems were difficult to use and that the user manual was complex; the majority used only the manual mode rather the program mode. The inhabitants of house E used the program mode, but the available schedules did not match their lifestyle.

\subsection{Indoor environment parameters}

\subsubsection{Air stuffiness and thermal comfort}

The concentrations of $\mathrm{CO}_{2}$ and the $\mathrm{T}$ and $\mathrm{RH}$ values measured in the main bedroom of each house during occupancy (Sum and Win) are presented in Table 4.

Table 4 - Descriptive statistics of $\mathrm{CO}_{2}$ level (ppm), $\mathrm{T}\left({ }^{\circ} \mathrm{C}\right)$ and $\mathrm{RH}(\%)$ measured weekly in the main bedrooms of six occupied houses by season. (Sum: summer; Win: winter; P25: $25^{\text {th }}$ percentile; P75: $75^{\text {th }}$ percentile; n.a.: not available)

The median $\mathrm{CO}_{2}$ levels were always below 1000 ppm and ranged between $351 \mathrm{ppm}$ (house $\mathrm{B}$ ) and 811 ppm (house A). These levels were significantly lower in summer than in winter $(\mathrm{p}<0.0001)$. The lowest levels were close to the measured outdoor level, and the highest levels were less than $2100 \mathrm{ppm}$. Houses $\mathrm{C}$ and $\mathrm{D}$ appeared to have less fresh air than the others because of their high interquartile temperature ranges. The median temperatures were between 20.3 and $25.7^{\circ} \mathrm{C}$ in summer and 19.5 and 21.6 in winter. Larger variation in temperature was observed in winter $\left(8\right.$ to $\left.15^{\circ} \mathrm{C}\right)$ than in summer $\left(3\right.$ to $\left.8{ }^{\circ} \mathrm{C}\right)$. The median RH values were between 45 and 58\% in summer and between 29 and 34\% in winter. As expected, the $\mathrm{T}$ and $\mathrm{RH}$ values were significantly higher in summer than in winter $(\mathrm{p}<0.0001)$. 
According to the inhabitants, the global thermal comfort of their houses ranged between "rather satisfactory" and "satisfactory" in the summer (T and RH were -omfortable") and between "somewhat dissatisfied" and "satisfied" in winter (T was -omfortable", but RH was fairly low). The most discomfort was experienced in winter.

\subsubsection{Indoor air quality}

Table 5 presents the median TVOC levels and the concentrations of the individual VOC and aldehydes measured weekly in the main bedrooms of the seven houses in the pre-occupancy stage and during occupancy.

Table 5- Indoor TVOC, VOC and aldehyde levels $\left(\mu \mathrm{g} / \mathrm{m}^{3}\right)$ measured weekly in seven new low-energy houses at the pre-occupancy stage (Pre) and during occupancy (Sum: summer; Win: winter). LI: Limit of identification $\left(<1 \mu \mathrm{g} / \mathrm{m}^{3}\right)$; LD: limit of detection; LQ: limit of quantification; n.a.: not available; n.m.: not measured; Q.F.: quantification frequency

In the pre-occupancy stage, the median TVOC levels were low in houses A and B (less than $150 \mu \mathrm{g} / \mathrm{m}^{3}$ ) and high in the other houses (between 500 and more that $3000 \mu \mathrm{g} / \mathrm{m}^{3}$ ). In houses C, D and E, the TVOC concentrations were higher in pre-occupancy than during occupancy.

Forty-four VOCs and seven aldehyde compounds in ten families were identified and quantified at least once. The number of these compounds varied between 20 and 35 per house. Seventeen of the 20 targeted compounds measured during the national survey of IAQ in dwellings in France were quantified, and three were never detected (2-butoxy ethyl acetate, 1-methoxy-2-propanol, 1-methoxy-2-propyl acetate). The compounds were split into two groups by quantification frequency: the most frequently detected (in at least $56 \%$ of samples; 14 VOCs: 1,2,4-trimethylbenzene, alkylbenzenes, alpha-pinene, benzene, camphene, n-decane, n-undecane, ethylbenzene, limonene, pentane, styrene, toluene, m- and p-xylene, and o-xylene; five aldehydes: acetaldehyde, acrolein, formaldehyde, hexaldehyde and isovaleraldehyde) and the least frequently detected (in at most $39 \%$ of samples; 30 VOCs and two aldehydes). For the most frequently detected compounds, high levels were measured in the pre-occupancy stage in houses C, E and 
G and lower levels were measured in house A. During occupancy, eight compounds were always quantified. Hexaldehyde presented the highest concentrations in the majority of houses both before occupancy $\left(69.7-856 \mu \mathrm{g} / \mathrm{m}^{3}\right)$ and after $\left(36.1-104.9 \mu \mathrm{g} / \mathrm{m}^{3}\right.$ in summer and 14.6-96 $\mu \mathrm{g} / \mathrm{m}^{3}$ in winter). Formaldehyde was the only compound whose concentrations were systematically higher in summer than winter. Acetaldehyde, n-decane, n-undecane, alpha- pinene, 1,2,4-trimethylbenzene and o-xylene were also always measured. For the less frequently measured compounds, high levels were detected in the preoccupancy stage in houses $\mathrm{C}$ and $\mathrm{E}$. N-butyl acetate was quantified at high concentrations in only two buildings (548.1 $\mu \mathrm{g} / \mathrm{m}^{3}$ in occupied house $\mathrm{B}$ in winter and $108.2 \mathrm{in} \mu \mathrm{g} / \mathrm{m}^{3}$ in unoccupied house E). This compound is mainly used as a solvent or diluent in the cosmetics, clothing, automotive, food and pharmaceutical industries and in the production of liquid floor wax, photographic film and plastics [19] Here, this compound may be related to the use of perfume and/or cosmetics such as nail polish and nailpolish remover [20] because VOC sampling was carried out in the main bedrooms opening onto a private bathroom. In house B, the inhabitants declared daily use of perfume and hairspray during the week of measurement in winter. In house E, the inhabitants lived in the house during the two first days of the preoccupancy stage, when the MVHR system was switched off.

The mass concentrations of $\mathrm{PM}_{2,5}$ were always below $30 \mu \mathrm{g} / \mathrm{m}^{3}$ and ranged from 6 (house $\mathrm{C}$ ) to $28 \mu \mathrm{g} / \mathrm{m}^{3}$ (house B; Figure 4). The measured concentrations were higher in winter than in summer in houses A, B, $\mathrm{C}$ and $\mathrm{E}$ but not in house $\mathrm{F}$. This exception can be linked to the proximity of a construction site to house $\mathrm{F}$ during the summer. For all houses, the pre-occupancy concentrations of $\mathrm{PM}_{2,5}$ remained under $15 \mu \mathrm{g} / \mathrm{m}^{3}$ and never exceeded those levels during occupancy. The radon concentrations ranged between 7 and 66 $\mathrm{Bq} / \mathrm{m}^{3}$ and were highest in houses $\mathrm{B}$ and $\mathrm{E}$ and lowest in house $\mathrm{D}$ (Figure 5). In general, the radon concentrations were higher in the living room than in the main bedroom, except in house E. CO concentrations were measured during the winter in only three houses (B, D and E), all of which had wood stoves, and were near zero ppm, with a peak at 8 ppm measured immediately after lighting the wood stove in house D. 
Figure 4 - Weekly mass concentrations of $\mathrm{PM}_{2.5}\left(\mu \mathrm{g} / \mathrm{m}^{3}\right)$ measured in the living room for six houses during the pre-occupancy stage (Pre) and during occupancy (summer: Sum; winter: Win). n.a.: not available; n.m.: not measured

Figure 5 - Radon concentrations $\left(\mathrm{Bq} / \mathrm{m}^{3}\right)$ measured in the living room and in the main bedroom for six occupied houses. n.a.: not available

\section{Discussion}

\subsection{Assessment of the performance and the use of MVHR}

When the MVHR systems were switched off, the ACH of most of houses was less than $0.05 \mathrm{~h}^{-1}$ (except

for house $\mathrm{F}$, at $0.12 \mathrm{~h}^{-1}$ ), confirming that the buildings were highly airtight (as previously measured with a blower-door test). The average ACH generated by four adjusted MVHR systems before measurement (houses A, B, C and F) at the medium (most used) fan speed was compared to a rate of $0.5 \mathrm{~h}^{-1}$. This value corresponds to the median ACH value of French dwellings [13] and is frequently used in national standards/regulation in Europe [21]. A value of $0.5 \mathrm{~h}^{-1}$ was reached in houses B, C and $\mathrm{F}$ and exceeded in house A. The measured air exhaust rates for four adjusted MVHR systems before measurement (houses A, B, C and F) were compared to the French regulations concerning residential-building ventilation [14]. It appears that the achievable air exhaust rates and the minimum values of reduced rates were reached occasionally but not systematically for each house (Table 6). The average noise levels in the main bedrooms of the four houses were near $30 \mathrm{~dB}(\mathrm{~A})$ for the low fan speed). For the other fan speeds, higher noise levels (between 35 and $48 \mathrm{~dB}(\mathrm{~A})$ ) caused the inhabitants to complain, as in house B. Our observations were consistent with those of eight passive houses [22] and in recently built Dutch homes equipped with MVHR systems and natural and mechanical-exhaust ventilation [23]. Shortcomings such as insufficient ventilation, high noise levels, unclean systems and insufficient maintenance were common [23]. The recurring problem in MVHR-ventilated airtight buildings is not a technical shortcoming of the ventilation system itself; installer expertise and solid installation-qualification procedures are 
indispensable to MVHR success [24]. Finally, the inhabitants in our study found the ventilation system difficult to use, as previously shown in passive houses [25].

Table 6 - Comparison of the measured air exhaust rate $(1 / \mathrm{s})$ for four houses to the French regulations concerning residential-building ventilation [14].

\subsection{Comparison of our IAQ results to those of previous studies}

During the pre-occupancy stage, the instructions were as follows: absence of inhabitants, selection of the median fan speed for the MVHR system and no air-polluting activities such as painting, aerosol spraying and sanding. These instructions were followed in all but not for three houses: there was painting in house $\mathrm{C}$, the presence of inhabitants during the first 24 hours and painting in house $\mathrm{E}$ and the MVHR systems were switched off in houses E and G. Thus, the highest concentrations of the most common VOCs and aldehydes were measured in those houses, although the mass concentrations of $\mathrm{PM}_{2.5}$ were unchanged. The lowest concentrations were observed in house A, for which the estimated average $\mathrm{ACH}$ for the medium MVHR fan speed was nearly double $\left(0.9 \mathrm{~h}^{-1}\right)$ that of the other houses (approximately 0.5 $\mathrm{h}^{-1}$ ). Moreover, this house was investigated 13 months after its completion versus one month for the other houses. The geometric concentrations of TVOC and of the most commonly quantified VOCs and aldehydes of three unoccupied houses for which the instructions were followed (houses A, B and D) were calculated. VOCs and aldehydes were compared to data from previous studies. Our TVOC values obtained with a PID instrument and providing information on a given mixture of VOC cannot be compared with TVOC values obtained in other studies by using sampling on a sorbent and subsequent separation by gas chromatography. Those studies were conducted in unoccupied and ventilated dwellings less than one year old, which can be energy efficient (EE) and/or built with low-emissions material (LE) (Table 7). It appears that the concentrations of TVOC and the majority of aromatic hydrocarbons measured in our study were consistently lower than those reported by authors from other countries. The concentrations of other organic compounds were also always lower than those reported $[26,27,28]$. 
However, the concentrations of aldehydes, terpenes, aliphatic hydrocarbons and 1,2,4-trimethylbenzene were sometimes higher than those measured [10,29,30,31,32,33]. The concentrations of organic compounds measured in non-ventilated houses $(\mathrm{E}$ and $\mathrm{G})$ were higher than those reported in a new, unventilated Minergie home [8], except for alpha-pinene, formaldehyde and acetaldehyde.

Table 7 - Comparison of geometric concentrations of TVOC and of the most frequently quantified VOC and aldehydes in this study in three unoccupied houses (A, B and D) to the results of previous studies conducted in unoccupied and ventilated dwellings less than one year old. Some of these houses may have been energy-efficient and/or built with low-emitting material. n.m.: not measured

The arithmetic means of TVOC and the geometric means of the most frequently measured VOCs and aldehydes in occupied houses (A, B, C, D, E and F) in summer and in winter were compared (Table 8) to data from previous studies. Those studies were conducted in newly occupied homes and presented in a recent literature review [34]. Only studies conducted in occupied and ventilated dwellings less than one year old were selected, and a small number of studies in energy-efficient homes were added. Our TVOC concentrations were lower than those reported in 24 R-2000 standard homes in Canada [35], in two Minergie apartments in Switzerland [8] and in 292 dwellings in Japan [36]. Our results were similar to those measured in six apartments built with low emissions material in Finland [30]. The decrease in TVOC levels over time observed in houses C, D and E was also reported by other authors [35]. In R-2000 standard homes, TVOC concentrations were higher during the first week after closure and then decreased with time and became relatively stable approximately 40 days after closure, at approximately one quarter of the maximum observed level [6]. A 50\% decrease in TVOC levels was observed after seven days of strong ventilation [30]. All VOCs and aldehydes measured in our study presented concentrations lower than those reported by another authors $[36,37]$. The concentrations of ethylbenzene, styrene, toluene and limonene measured in our study were lower than those reported by any other study. For all other compounds, the concentrations were in the ranges of those measured in another studies $[10,11,30,35]$.

Table 8 - Comparison of the mean concentration of TVOC and geometric mean concentrations of the most frequently VOC and aldehydes quantified in this study in six occupied houses (A, B, C, D, E and F) in summer and winter with the results of previous studies conducted in newly occupied and ventilated 
dwellings less than one year old. Some of these houses may have been energy-efficient and/or built with low-emissions material. n.m.: not measured

\subsection{Comparison of our IAQ results to the standard French houses $F$ and the indoor air-quality guideline values used in France}

The values of $\mathrm{CO}_{2}$, VOC, aldehyde compounds, $\mathrm{PM}_{2.5}$ mass, radon concentrations, temperature and relative humidity in the occupied houses $(\mathrm{A}, \mathrm{B}, \mathrm{C}, \mathrm{D}, \mathrm{E}$ and $\mathrm{F})$ were compared to the IAQ of the standard French houses [12]. The standard French houses have an $\mathrm{ACH}$ of $0.5 \mathrm{~h}^{-1}$ [13] but are older than the houses in our study (half built before 1968), are under-equipped with MVHR (only 1.1\%), are built predominantly of masonry (only $6 \%$ wood frame), have higher occupation rates $(0.8)$ and allow smoking (34\% of homes have at least one smoker).

The median $\mathrm{CO}_{2}$ concentrations measured in summer and in winter in our study were lower than the national median $\mathrm{CO}_{2}$ level (756 ppm) for three houses (B, E and F) and between $756 \mathrm{ppm}$ and $1000 \mathrm{ppm}$ for the other houses (A, C and D). The seasonal variation in $\mathrm{CO}_{2}$ levels (lower in summer than in winter) is most likely related to the increased rate of air exchange in these houses in summer due to the opening of windows, as observed in another studies $[38,39]$. The occupants of our houses reported opening the windows more than one half hour per day in summer and rarely or almost never in winter, as in standard French houses [13], suggesting that the occupants of low-energy houses do not drastically change their usual ventilation behaviours. The comparison between the median temperatures and relative humidities measured in these houses and the median values of French dwellings are shown in Figure 6. Houses A, B and $\mathrm{F}$, but not houses $\mathrm{C}, \mathrm{D}$ and $\mathrm{E}$, exceeded the national median temperature. In contrast, only house $\mathrm{E}$ reached the national median relative humidity, specifically in winter.

Figure 6 - Comparison of weekly median $\mathrm{T}\left({ }^{\circ} \mathrm{C}\right)$ and $\mathrm{RH}(\%)$ measured in the bedroom for six occupied houses (Sum: summer; Win: winter) to the seasonal values measured in standard French dwellings (CNL). n.a.: not available 
The median ratios of the average concentrations of $\mathrm{VOC}$, aldehydes, $\mathrm{PM}_{2.5}$ and radon measured in all occupied houses to the national median concentration in standard French dwellings are presented in Figure 7. Compared to the median concentration of indoor air pollutants in standard French dwellings, the average concentrations of $\mathrm{PM}_{2.5}$, radon and two aromatic hydrocarbons compounds (benzene and toluene) were lower, whereas the concentration of formaldehyde was not significantly different. The concentrations of three aromatic hydrocarbon compounds (ethylbenzene, m- and p-xylene and 1,2,4trimethylbenzene), one aldehyde (acrolein) and one aliphatic hydrocarbon compound (n-decane) were less than 1.5 times higher than the national levels. Other compounds were more markedly elevated in concentration, including hexaldehyde (up to 4.7 times higher) and n-decane (up to two times higher) and (to a lesser extent) styrene, o-xylene and acetaldehyde (between 1.7 and 1.5 times higher).

Figure 7 - Median ratio of the average concentrations of VOC, aldehydes, $\mathrm{PM}_{2.5}$ and radon measured in six occupied houses to the national median concentration in French dwellings

Although it is difficult to explain these differences, the high levels of hexaldehyde may be associated with the use of wood as the main construction material [27]. The degradation of the wood (composite wood products and lumber) or its secondary metabolites is most likely responsible for the presence of the aldehydes [40]. High aldehyde levels may also be related to the use of paints and varnishes for wood $[41,42,43]$, the presence of new materials (less than one year old) such as particle-board furniture [44] and the surface coverings of walls [45], floors and ceilings [46]. The recent use of products containing solvents (paint, adhesives, etc.) may cause elevated concentrations of n-undecane and n-decane [47]. Formaldehyde was present in homes in our study at levels comparable to other French homes, although higher levels were expected because of the age of the buildings and materials (less than one year) and the high use of wood. The low concentration of radon and the low mass concentration of $\mathrm{PM}_{2.5}$ may be associated with the very high airtightness of these buildings compared to average French homes. Based on the living room's radon measurement (on ground level), the mean concentration reaches $16 \mathrm{~Bq} / \mathrm{m}^{3}$ for measurement period in spring, $35 \mathrm{~Bq} / \mathrm{m}^{3}$ for measurement period in fall. The only one measure available for measurement period in fall/winter is equal to $43 \mathrm{~Bq} / \mathrm{m}^{3}$ (for house $\mathrm{B}$ ). According this observation, 
occupants' window opening behaviour depending on season could have an impact on radon concentration but this hypothesis can't be validated because their behaviours haven't been recorded during the radon measurement period. Finally, the low concentrations of aromatic hydrocarbons may be related to the general absence of attached garages, which are known to be an important source of those compounds $[48,49,50]$. The high concentrations of benzene and toluene in house A, the only building with an attached garage, seem to reinforce this hypothesis. The drier air might be associated with better ventilation in houses equipped with MVHR systems [51] and with a lower production of water vapour because of the under-occupation of these buildings.

The concentrations of formaldehyde, benzene and radon did not exceed the indoor air-quality guideline values currently used in France (respectively $30 \mu \mathrm{g} / \mathrm{m}^{3}$ long-term exposure, $1^{\text {st }}$ January $2015,5 \mu \mathrm{g} / \mathrm{m}^{3}$ long-term exposure, $1^{\text {st }}$ January 2013 [52] and $400 \mathrm{~Bq} / \mathrm{m}^{3}$ for a public building according [53]). The concentrations of acetaldehyde, xylenes, styrene and toluene were within the European guideline values [54] (respectively $200 \mu \mathrm{g} / \mathrm{m}^{3}, 200 \mu \mathrm{g} / \mathrm{m}^{3} 250 \mu \mathrm{g} / \mathrm{m}^{3}$ and $300 \mu \mathrm{g} / \mathrm{m} 3$ ), but the level of $\mathrm{PM}_{2.5}$ exceeded the WHO air-quality guidelines [55] (10 $\mu \mathrm{g} / \mathrm{m}^{3}$ annual mean).

\subsection{Temporal variation of IAQ in occupied houses}

The temporal variation in IAQ in the six occupied houses was calculated based on the concentration ratio between the measurements made during the first and second surveys for $\mathrm{PM}_{2.5}$ and VOC and aldehyde compounds in at least four houses (Figure 8). For VOC and aldehydes, the ratios were calculated only for each compound measured in each survey. The first survey was conducted in summer and the second in winter, except for houses D and F. The interval between the surveys was three months for house D, four months for house $\mathrm{C}$ and six months for houses $\mathrm{A}, \mathrm{B}, \mathrm{E}$ and $\mathrm{F}$. The median of the ratios for each of the six houses was calculated.

Figure 8 - Ratio of the concentrations of VOC, aldehydes and $\mathrm{PM}_{2.5}$ measured during the second survey to those measured during the first survey for each of six occupied houses and ratio of the median concentrations for all houses 
The majority of VOC and aldehydes exhibited lower concentrations in the second survey (median ratio less than 1), or similar in the case of 1,2,4-trimethylbenzene, whereas the opposite trend was observed for n-undecane and $\mathrm{PM}_{2.5}$ (median ratio greater than 1).

The concentrations of toluene, styrene, xylenes, ethylbenzene, terpenes (alpha-pinene and limonene) and acetaldehyde decreased for most of the houses, suggesting that these compounds were mainly emitted by building sources such as building material, insulation, decoration, surface coatings, furniture and other sources. The concentrations of these compounds decreased with the decreasing of emission-source strength over time. Those observations were consistent with another authors [35], which showed significantly reduced concentrations of styrene, p-xylene and alpha pinene over one year in new homes. Another authors [37] also observed over a period of one year in a wood detached house that concentrations of seven COV compounds, including toluene, alpha-pinene and limonene, exhibited a declining trend with time. Several authors have shown that aldehyde concentrations can be influenced by building materials and human activities [30,44]. In our study and because of the recent construction of the buildings, building materials appear to have been the principal source of high aldehyde concentrations $[45,46]$. The decreased hexaldehyde concentrations may be correlated with the increased age of the furniture and the ground/wall/ceiling coverings [46], but after more than one year, none of these materials has any influence on hexaldehyde levels [44]. In houses D and F, the higher levels of formaldehyde observed during the second survey (in summer) corroborated the observations of other authors [31,56,57]. This increase may be attributed principally to the influence of temperature on VOC emissions from materials [58] and secondarily to the reactions between organic compounds (especially terpenes) and ozone $[59,60,61]$. A study carried out in new single - family homes in California showed that as outdoor air exchange rates decrease or the indoor temperature increases, the indoor concentrations of formaldehyde increase [62].

The highest concentrations of benzene and toluene relative to national standards were observed in house A (ratios of 3.9 and 1.3, respectively) and seem to be linked to the presence of an attached garage. Several 
authors $[48,49,50]$ have shown that many pollutant sources, such as gasoline-fired engines (automobiles, gardening tools such as lawnmowers, etc.), fuel, paint and solvent are commonly stored or used in residential attached garages and may be an important source of monocyclic aromatic hydrocarbons.

The high ratios of n-undecane concentrations relative to national standards in houses A, B and E (1.9, 7.0 and 4.6, respectively; attributable to painting that occurred in houses B and E between the two surveys) explained the high median ratio level observed for all houses (median ratio $=1.3$ ). The relatively high levels of $n$-decane in houses B and E (ratios of 4.7 and 2.1, respectively) support this hypothesis.

Increased concentrations of $\mathrm{PM}_{2.5}$ (median = 1.8) were observed in all buildings except house $\mathrm{F}$ and seem to be seasonal. The influence of season on the particulate-matter concentrations has previously been reported $[63,64]$ and appears to be linked to different ventilation practices in summer and winter. According to a meta-analysis conducted in Europe [65], the highest particulate-matter infiltration was observed in summer, with the lowest infiltration in winter. Because of the increased ventilation in summer from the opening of windows, indoor PM levels were highly correlated with outdoor PM levels, whereas in winter, PM levels were more strongly influenced by human indoor activities. In our study, indoor and outdoor $\mathrm{PM}_{2.5}$ concentrations showed a strong positive correlation in summer $(\mathrm{r}=0.98)$ and a weak positive correlation in winter $(\mathrm{r}=0.11)$. Finally, the highest ratio of $\mathrm{PM}_{2.5}$ concentrations, observed in houses $\mathrm{B}$ and $\mathrm{E}(\geq 3)$, seems to be related to the use of wood for heating during the second survey (in winter). The impact of the wood heating system on indoor $\mathrm{PM}_{10}, \mathrm{PM}_{2.5}$ and $\mathrm{PM}_{1}$ concentrations has been shown previously [66].

\section{Conclusions}

Seven newly built, low-energy single-family detached houses in France conform to the highly airtight and energy-efficient standards set forth in RT2012 were investigated during the pre-occupancy stage and during occupancy in summer and winter. Because of the limited sample size, caution must be taken and 
the findings can't be generalized. The following conclusions can be drawn from the present study but contribute significantly to knowledge about IAQ and occupant's comfort in energy efficient homes.

Several IAQ-indicator measurements show that the concentrations of aromatic hydrocarbons, terpenes, alkanes and aldehydes were higher in the pre-occupancy stage than during occupancy. The concentrations of some aromatic hydrocarbons (toluene, ethylbenzene, xylenes, styrene), terpenes (alpha-pinene, limonene) and acetaldehyde decreased with time, possibly in relation to the decrease in emissions from building materials over time. The concentrations of alkanes (n-decane and n-undecane), benzene and major aldehydes (formaldehyde and hexaldehyde) may increase temporarily in response to human activities. The $\mathrm{PM}_{2.5}$ levels increased during occupancy and appear to be related, in summer, to the outdoor $\mathrm{PM}_{2.5}$ levels via an increased infiltration level and with indoor human activities in winter. The air temperature and relative humidity were higher in summer than in winter (between 20 and $26{ }^{\circ} \mathrm{C}$ in summer, versus between 20 and $22{ }^{\circ} \mathrm{C}$ in winter between 45 and $58 \% \mathrm{RH}$ versus 29 and $34 \% \mathrm{RH}$, respectively).

Compared to the IAQ of standard French houses, the median concentrations of $\mathrm{PM}_{2.5}$, radon, benzene and toluene were lower in the houses studied. The air temperature and the formaldehyde concentrations were similar to those found in typical French houses, whereas the concentrations of ethylbenzene, m- and pxylene, 1,2,4-trimethylbenzene and acrolein were slightly higher (less than 1.5-fold). In contrast, concentrations of hexaldehyde, acetaldehyde, styrene, o-xylene, n-decane and n-undecane exceeded the levels in typical French dwellings by more than $50 \%$. The concentrations of these compounds seem to be related to new construction. The relative humidity of the study houses was lower than in French dwellings, possibly due to the constant and permanent ventilation occurred by the MVHR systems and due to limited water production linked to the under-occupancy of the study houses. The levels of indoor pollutants in the study houses were within the guideline values for indoor air quality used in France, but the $\mathrm{PM}_{2.5}$ level exceeded the levels set by WHO recommendations. The MVHR systems exhibited commonly reported shortcomings but provided sufficient $\mathrm{ACH}(\geq 0.5 \mathrm{~h}-1)$. In summer, the inhabitants improved the houses' ventilation by opening windows, as in conventional dwellings. MVHR systems 
seem to be difficult to use, and high noise levels can be produced at the highest fan speed. Finally, in airtight buildings, the mechanical ventilation systems must work constantly; if they shut down, without ventilation through open windows, indoor air quality can be become poor and present a risk to human health.

\section{Acknowledgements}

This study was supported by the Scientific and Technical Building Centre (CSTB) through the lead author's research programme and by the French Observatory of Indoor Air Quality (OQAI), which is funded by the Ministries of Housing, Environment and Health; the Environment and Energy Management Agency (ADEME); the French agency for Food, Environmental and Occupational Health Safety (ANSES); and the CSTB. The authors thank the owners and the tenants of the study houses for their time and for opening their homes for this study. Sample analyses were conducted by three laboratories (Paris Hygiene Laboratory for $\mathrm{PM}_{2.5}$ concentrations, chemical laboratory of CSTB for the VOC and aldehyde analyses, Dosirad for radon measurements).

\section{References}

[1] Grenelle de l'Environnement. Lutter contre les changements climatiques et maîtriser l'énergie Rapport de synthèse du Groupe 1. 2008.

[2] ADEME. Les chiffres clés du bâtiment Énergie-Environnement : Edition 2011, 2012.

[3] Loi Grenelle 1. Loi n ${ }^{\circ} 2009-967$ du 3 août 2009 de programmation relative à la mise en œuvre du Grenelle de l'environnement (1). JORF n 179 du 5 août 2009, p 13031. 
[4] Crump D, Dengel A and Swainson M. Indoor air quality in highly energy efficient homes - a review. NHBC Foundation report NF18, Published by IHS BRE Press on behalf of the NHBC Foundation, ISBN: 978-1-84806-104-0, 2009.

[5] Feist W, Werner J. Ventilation concept, indoor air quality and measurement results in the "Passivhaus Kranichstein". Proceeding of the 15th AIVC Conference, Buxton, Great Britain, 1994; 1: 321-32.

[6] Shaw CY, Magee RJ, Swinton MC, Riley M, Robar J. Canadian experience in healthy housing. International symposium on current status of indoor air pollution by organic compounds and countermeasures for healthy housing, Tokyo, Japan, 2001:31-35.

[7] Wendt R, Aglan H, Livengood S, Khan M, Ibrahim, E. Indoor Air Quality of an Energy-Efficient, Healthy House with Mechanically Induced Fresh Air. ASHRAE 2004 Annual Meeting, Nashville,110,2: $1-8$.

[8] Dalang F, Bianco MA. Pour un air sain dans des bâtiments durables, Pollution intérieure dans trois maisons familiales, étude pilote pour la surveillance de la qualité de l'air dans des habitations. Rapport Service cantonal de toxicologie industrielle et de protection contre les pollutions intérieures, 2006.

[9] Moriske HJ, Wensing M. Untersuchungen zur raumlufthygienischen Situation in energetisch sanierten Altbauten und in einem Passivhaus. Gefahrst Reinhalt L 2007; 67(3):85-90.

[10] Dalang F. La qualité de l'air intérieur dans les logements du quartier du Pommier, Résultats d'une campagne de surveillance de la qualité de l'air intérieur 2004 et 2005. Rapport Service cantonal de toxicologie industrielle et de protection contre les pollutions intérieures, 2007.

[11] Engelmann P, Roth K, Tiefenbeck V. Comfort, indoor air quality, and energy consumption in low energy homes, NREL Report No. SR-5500-56023; DOE/GO-102013-3746, 2013. 
[12] Kirchner S, Arènes JF, Cochet C, Derbez M, Duboudin C, Elias P et al. État de la qualité de l'air dans les logements français. Environ Risque Sante 2007; 6(4):259-69.

[13] Lucas JP, Ramalho O, Kirchner S, Ribéron J. Etat de la ventilation dans le parc de logements français, CSTB, report N DESE/SB-2009-37; 2009.

[14] Arrêté du 24 mars 1982 modifié par l'arrêté du 28 octobre 1983 (JORF du 15 novembre 1983) relatif à l'aération des logements: aération générale ou permanente, aération permanente pouvant être limitée à certaines pièces. JORF du 27 mars 1989, p942

[15] Derbez M, Berthineau B, Cochet V, Lethrosne M, Pignon C, Ribéron J, Kirchner S. Méthodologie d'évaluation de la qualité de l'air intérieur, du confort des occupants et des consommations énergétiques réelles des bâtiments d'habitation performants en énergie. Environ Risque Sante 2012;11(1): 40-51.

[16] Ramalho O, Derbez M, Grégoire A, Garrigue J, Kirchner S. French permanent survey on Indoor Air Quality - Part. 1 : Measurement protocols and quality control. Proceedings of the 8th International Conference of Healthy Buildings, Lisbon, Portugal. 2006;vol 3: 321-26.

[17] AFNOR. Ambient air quality - Standard gravimetric measurement method for the determination of the $\mathrm{PM}_{2,5}$ mass fraction of suspended particulate matter (AFNOR standard NF EN 14907); 2006.

[18] Derbez M, Grégoire A, Ramalho O, Garrigue J, Kirchner S. French permanent survey on Indoor Air Quality : Part. 2 : Questionnaires and validation procedure of collected data. Proceedings of the 8th International Conference of Healthy Buildings, Lisbon, Portugal. 2006;3:327-32.

[19] Health Council of the Netherlands: Dutch Expert Committee on Occupational Standards. n-, iso-, sec-, and tert-Butyl acetate; Health-based recommended occupational exposure limit. The Hague: Health Council of the Netherlands, 2001; publication no. 2001/03OSH. 
[20] Toy NJ. Final report on the safety assessment of ethyl acetate and butyl acetate. J Am Coll Toxicol 1989;8: 681-705.

[21] Dimitroulopoulou C. Ventilation in European dwellings: A review. Build Environ 2012;47:109-25.

[22] Larsen TS, Jensen RL, Daniels O. The Comfort Houses. Measurements and analysis of the indoor environment and energy consumption in 8 passive houses 2008-2011. DCE Technical report N 145. ISSN 1901-726X, 2012.

[23] Balvers J, Bogers R, Jongeneel R, van Kamp I, Boerstra A, van Dijken F. Mechanical ventilation in recently built Dutch homes: technical shortcomings, possibilities for improvement, perceived indoor, environment and health effects. Architect Sci Rev 2012;55(1): 4-14.

[24] Van der Pluijm WMP. The robustness and effectiveness of mechanical ventilation in airtight dwellings. A study to the residential application of mechanical ventilation with heat recovery in the Netherlands. Eindhoven University of Technology, Master's Thesis; 2010.

[25] Hasselaar E. Health risk associated with passive houses : an exploration. Proceedings of the $11^{\text {th }}$ international Conference on Indoor Air Quality and Climate, Copenhagen, Denmark, 2008: paper ID 689.

[26] Crump D, Squire R, Yu C. Sources and Concentrations of Formaldehyde and Other Volatile Organic Compounds in the Indoor Air of Four Newly Built Unoccupied Test Houses. Indoor Built Environ $1997 ; 6: 45-55$.

[27] Hodgson AT, Beal D, McIllaine JER. Sources of formaldehyde, other aldehydes and terpenes in a new manufactured house. Indoor Air 2002;12:235-42.

[28] Hodgson AT, Rudd AF, Beal D, Chandra S. Volatile organic compound concentrations and emission rates in new manufactured and site-built houses. Indoor Air 2000;10:178-92. 
[29] Brown SK. Volatile organic pollutants in new and established buildings in Melbourne, Australia. Indoor Air 2002;12(1):55-63.

[30] Tuomainen M, Pasanen AL, Tuomainen A, Liesivuoria J, Juvonend P. Usefulness of the Finnish classification of indoor climate, construction and finishing materials: comparison of indoor climate between two new blocks of flats in Finland. Atmos Environ 2001;35(2):305-13.

[31] Järnström H, Saarela K, Kalliokoski P, Pasanen AL. Reference values for indoor air pollutant concentrations in new, residential buildings in Finland. Atmos Environ 2006;40(37):7178-91.

[32] Lim S, Lee K, Seo S, Jang S. Impact of regulation on indoor volatile organic compounds in new unoccupied apartment in Korea. Atmos Environ 2011;45(11):1994-2000.

[33] Kim SS, Kang DH, Choi DH, Yeo MS, Kim KW. Comparison of strategies to improve indoor air quality at the pre-occupancy stage in new apartment buildings. Build Environ 2008;43(3):320-8.

[34] Mandin C, Maupetit F. Qualité de l'air intérieur dans les bâtiments neufs : données disponibles et spécificités. Pollution Atmospherique 2011;209:47-56.

[35] Park JS, Ikeda K. Variations of formaldehyde and VOC levels during 3 years in new and older homes. Indoor Air 2006;16(2):129-35.

[36] Gusdorf J., Parekh A. Energy efficiency and Indoor air quality in R-2000 and conventional new houses in Canada, Proceedings of the 11th biennial Summer Study on Energy Efficiency in Buildings, Pacific Grove, USA. 2000,1.101-1.112.

[37] Yamaguchi T, Nakajima D, Ezoe Y, Fujimaki H, Shimada Y, Kozawa K et al. Measurement of volatile organic compounds (VOCs) in new residential buildings and VOCs behavior over time, J UOEH.2006; 28(1):13-27. 
[38] Wallace L, Emmerich SJ, Howard-Reed C. Continuous measurements of air change rates in an occupied house for 1 year : the effect of temperature, wind, fans, and windows. J Expo Sci Environ Epidemiol 2002;12:296-306.

[39] Howard-Reed C, Wallace LA, Ott WR. The effect of opening windows on air change rates in two homes. J Air Waste Manage 2002;52:147-59.

[40] Baumann MGD, Lorenz LE, Batterman S.A. Aldehyde emissions from particleboard and medium density fiberboard products. Forest Prod J 2000;50(9):75-82.

[41] Afshari A, Lundgren B, Ekberg LE. Comparison of three small chamber test methods for the measurement of VOC emission rates from paint. Indoor Air 2003;13(2):156-65.

[42] Chang JCS, Guo Z. Emissions of odorous aldehydes from alkyd paint. Atmos Environ 1998;32: 3581-6.

[43] Fortmann R, Roache N, Chang JCS, Guo Z. Characterization of emissions of volatile organic compounds from interior alkyd paint. J Air Waste Manage 1998;48(10):931-40.

[44] Dassonville C, Demattei C, Laurent AM, Le Moullec Y, Seta1 N, Momas I. Assessment and predictor determination of indoor aldehyde levels in Paris newborn babies' homes. Indoor Air 2009;19 (4):314-23.

[45] Clarisse B, Laurent AM, Seta N, Le Moullec Y, Hasnaoui A El, Momas I. Indoor aldehydes: measurement of contamination levels and identification of their determinants in Paris dwellings. Environ Res 2003;92:245-53.

[46] Marchand C, Le Calve S, Mirabel P, Glasser N, Casset A, Schneider N. et al. Concentrations and determinants of gaseous aldehydes in 162 homes in Strasbourg (France). Atmos Environ. 2008;42:50516. 
[47] Brown SK, Sim MR, Abramson MJ, Gray CN. Concentrations of Volatile Organic Compounds in Indoor Air - A Review. Indoor Air 1994; 4:123-34.

[48] Graham LA, Noseworthy L, Fugler D, O'Leary K, Karman D, Grande C. Contribution of vehicle emissions from an attached garage to residential indoor air pollution levels. J Air Waste Manage 2004;54 (5):563-84.

[49] Batterman S, Hatzivasilis G, Jia C. Concentrations and emissions of gasoline and other vapors from residential vehicle garage. Atmos Environ 2006;40: 1828-44.

[50] Dodson RE, Levy JI, Spengler JD, Shine JP, Bennett DH. Influence of basements, garages, and common hallways on indoor residential volatile organic compound concentrations. Atmos Environ 2008;42:1569-81.

[51] Howieson SG, Lawson A, McSharry C, Morris G, McKenzie E, Jackson J. Domestic ventilation rates, indoor humidity and dust mite allergens - Are our homes causing the asthma pandemic. Build Serv Eng Res Technol 2003;24(3):137-47.

[52] Décret n 2011-1727 du 2 décembre 2011 relatif aux valeurs-guides pour l'air intérieur pour le formaldéhyde et le benzène, JORF $N^{\circ} 0281$ du 4 décembre 2011 page 20529.

[53] Arrêté du 22 juillet 2004 relatif aux modalités de gestion du risque lié au radon dans les lieux ouverts au public. JORF $\mathrm{N}^{\circ} 185$ du 11 aout 2004, page 14359.

[54] European Commission, JRC. The INDEX Project: Summary of recommendations and management options, December 2004.

[55] WHO. Air quality guidelines. Global update 2005. Particulate matter, ozone, nitrogen dioxide and sulfur dioxide, Copenhagen, WHO Regional Office for Europe, ISBN 978928902192 0, 2006 
[56] Reponen T, Raunemaa T, Savolainen T, Kalliokoski P. The effect of material ageing and season on formaldehyde levels in different ventilation systems. Environ Int 1991;17:349-55.

[57] Raw GJ, Coward SKD, Brown VM, Crump DR. Exposure to air pollutants in English homes. J Expo Sci Environ Epidemiol 2004;14:85-94.

[58] Wolkoff P. Impact of air velocity, temperature, humidity and air on long-term VOC emissions from building products. Atmos Environ 1998;32:2659-68.

[59] Weschler CJ, Schields HC. Potential reactions among indoor air pollutants. Atmos Environ 1997;31:3487-95.

[60] Weschler CJ, Clausen PA, Wilkins CK, Nielsen GD. Formation of strong airway irritants in terpene/ozone mixtures. Indoor Air 2000;10:82-91.

[61] Weschler CJ. Ozone in indoor environments: concentration and chemistry. Indoor Air 2000;10:26988.

[62] Offermann FJ. Ventilation and Indoor Air Quality in New Homes. California Air Resources Board and California Energy Commission, PIER Energy - Related Environmental Research Program. Collaborative Report. CEC - 500 - 2009 - 085. 2009.

[63] Fromme H, Twardella D, Dietrich S, Heitmann D, Schierl R, Liebl B et al.. Particulate matter in the indoor air of classrooms - exploratory results from Munich and surrounding area. Atmos Environ 2007;41(4):854-66.

[64] Keeler GJ, Dvonch T, Yip FY, Parker EA, Israel BA, Marsik FJ et al. Assessment of personal and community-level exposure to particulate matter among children with asthma in Detroit, Michigan, as part of Community Action Against Asthma (CAAA). Environ Health Persp 2002;110 (Suppl. 2):173-81. 
[65] Hänninen O, Hoek G, Mallone S, Chellini E, Katsouyanni K, Gariazzo C et al. Seasonal patterns of outdoor PM infiltration into indoor environments: review and meta-analysis of available studies from different climatological zones in Europe. Air Qual Atmos Health 2011;4:221-33.

[66] Nasir ZA, Colbeck I. Particulate pollution in different housing types in a UK suburban location, Sci Total Environ 2013;445-446:165-76. 
Indoor air quality and comfort in seven newly built, energy-efficient houses in France

DERBEZ Mickaël $1^{1}$ (corresponding author)

mickael.derbez@,cstb.fr

telephone : +3316468 8989, Fax : +33164688823

BERTHINEAU Bruno ${ }^{1}$

bruno.berthineau@cstb.fr

COCHET Valérie ${ }^{1}$

valerie.cochet@.cstb.fr

LETHROSNE Murielle $^{1}$

PIGNON Cécile ${ }^{1}$

cecile.pignon@cstb.fr

RIBERON Jacques ${ }^{1}$

jacques.riberon@cstb.fr

KIRCHNER Severine ${ }^{1}$

severine.kirchner@cstb.fr

${ }^{1}$ Université Paris-Est, Centre Scientifique et Technique du Bâtiment - Observatoire de la Qualité de l'Air Intérieur - 84, avenue Jean Jaurès - Champs sur Marne - 77477 Marne la Vallée cedex 2 - FRANCE 


\section{Introduction}

Because of the global warming, many governments have taken action to reduce anthropogenic greenhouse-gas emissions, to promote energy efficiency and to support for renewable energy. In France, the residential and commercial building sector is responsible of $23 \%$ of national greenhouse-gas emissions and is the largest energy consumer, accounting for $43 \%$ of energy consumption in the country in 2007 [1]. In 2011, the average unit energy intensity of the residential sector was $190 \mathrm{kWh} / \mathrm{m}^{2}$, higher than that of the commercial sector [2]. In this context, France has pledged to reduce greenhouse-gas emissions by $75 \%$ by 2050 and to reduce building energy consumption by $38 \%$ by 2020 [3]. Existing structures are being refurbished to increase energy efficiency at an accelerating rate, and as of 2013, all newly constructed buildings must meet the French 2012 thermal-regulation standards (RT 2012) for buildings. Although these new airtight buildings must have a primary conventional-energy consumption not exceeding $50 \mathrm{kWh} / \mathrm{m}^{2}$ per year, there are no requirements directly protecting the health and wellbeing of occupants. Moreover, the only literature review on indoor air quality (IAQ) in highly energy-efficient houses [4] concludes that "with regard to indoor air quality, there is a dearth of information relating to highly efficient structures". The authors note that it is difficult to extrapolate the results of studies of the construction of airtight buildings in colder climates (Canada, Central Europe and northern USA) to other countries because of differences in climate, construction practices, indoor sources depending of what people purchase on their homes and the social and economic conditions of the occupants. Finally, a small number of studies have investigated indicators of IAQ $[5,6,7,8,9,10,11]$, but none has conducted an IAQ longitudinal survey and compare their results with those of standard buildings.

The objective of the present study, which was funded by the French Observatory of Indoor Air Quality (OQAI in French), is to evaluate the IAQ and the occupants' comfort in seven low-energy, newly built houses in France. The survey was conducted during the pre-occupancy stage and during occupancy in summer and winter. The concentrations of several IAQ indicators and the indoor environmental parameters were measured during occupation. These results were compared to the IAQ of standard 
French houses [12], to the results of previous studies conducted in new dwellings and to the IAQ guideline values currently used in France. The air changes per hour (ACH) from mechanical ventilation with heat recovery (MVHR) were measured and compared to those of standard French homes [13]. The air-exhaust rates were compared to the French standards [14] for minimal airflow for dwellings according to the number of habitable rooms. The noise levels were measured, and the occupants' perceptions were evaluated with a questionnaire.

\section{Materials and methods}

A recently developed method for assessing IAQ, occupant comfort and energy consumption was applied in this study. A detailed description of sampling and measurement techniques has been presented elsewhere [15]. A short overview of the analytical procedures and the sampling strategy is given below.

\subsection{Description of the seven single-family detached houses}

Seven newly built, single-family detached houses in four regions of France (Centre, Pays-de-la-Loire, Ilede-France and Rhône-Alpes) were investigated in this study (Table 1).

Table 1 - Main characteristics of the seven new single-family detached houses investigated in this study in terms of construction, equipment and occupancy

The buildings had one or two stories, and one had an attached garage (A). All houses were constructed in accordance with an energy-efficient building certification such as the French BBC-Effinergie certification or the German Passivhaus certification. Three houses were certified (A: BBC-Effinergie; C and D: Passivhaus); house B's certification process was on-going, and the builders or owners of the other houses are not pursuing certification. Houses F and G satisfied the requirements of all 14 targets of the French High Environmental Quality Programme (HQE). The airtightness of all buildings was measured with a 
blower-door test between 0.29 and $3.33 \mathrm{vol} / \mathrm{h}$ under 50 Pascal pressure $\left(0.06\right.$ and $0.41 \mathrm{~m} / \mathrm{h} \cdot \mathrm{m}^{2}$ under 4 Pascal pressure). The houses' annual consumption of conventional primary energy (heating, cooling, ventilation, auxiliaries, hot water production, lighting facilities) was between 46 and $79 \mathrm{kWh} / \mathrm{m}^{2} /$ year. These houses were well within the requirements of the French 2005 thermal regulations (RT 2005) for buildings (airtightness less than $0.8 \mathrm{~m} / \mathrm{h} \cdot \mathrm{m}^{2}$ under $4 \mathrm{~Pa}$ and annual consumption of conventional primary energy less than $150 \mathrm{kWh} / \mathrm{m}^{2} /$ year). The houses also qualified as highly energy-efficient houses as defined by the French 2012 thermal regulation (RT 2012) because of their high airtightness (under 0.6 $\mathrm{m}^{3} / \mathrm{h} \cdot \mathrm{m}^{2}$ under $4 \mathrm{~Pa}$ ) and their theoretical low energy consumption (an annual consumption of conventional primary energy equal or less than $50 \mathrm{kWh} / \mathrm{m}^{2} /$ year). All of the houses were wood frame except for house A (stone) and used mineral (A, F and G) or vegetable (B, C, D and E) insulating material. All of the houses were equipped with an MVHR system with two, three or four normal fan speeds and occasionally one boost setting. The heating systems were mostly heat pumps (A, C, D, F and G) or wood stoves (B and E). House D had a wood stove for enjoyment rather than function. Hot water was mainly provided by solar panels with electric boosters (B, C, D, F and G) except in two houses (thermodynamic in house A and electric in house E). All of the houses but A had products and materials described by the manufacturers as low volatile-organic-compound-emitting. The inhabitants were families of 2-4 non-smokers, except for house G, which remained unoccupied during this study. The occupation rates were often lower than the median occupation rate (0.8) of the standard French houses [13] suggesting that these houses were under-occupied or were larger than an average French home.

\subsection{Measurement protocol}

The IAQ and indoor environmental parameters was monitored between February 2009 and July 2010 (Figure 1) just after the houses' completion (except for house A, completed in March 2008) for less than one year each. The IAQ was monitored in the main bedroom and in the living room and kitchen 
(collectively called living room") for three weeks in each building in the pre-occupancy stage and during occupancy (summer: Sum; winter: Win) except in houses F and G. The ACH, the air exhaust rates and the level of noise were determined simultaneously in the pre-occupancy stage. The temperature, the relative humidity and the concentration of radon were measured only in occupied houses. The MVHR systems were switched on during these investigations at the medium normal fan speed during the pre-occupancy stage (except for houses E and G, where the MVHR systems were turned off) and in manual or automatic mode during occupancy.

Figure 1 - Weekly investigation and moving dates of the seven new single-family detached houses between February 2009 and July 2010

The strategy of sampling / measurement and the accuracy/uncertainty of the indoor air quality parameters are presented in Table 2 .

Table 2 - Strategy of sampling/measurement and accuracy of indoor air quality parameters

Every ten minutes during the investigation, total volatile organic compounds (TVOC in toluene equivalent in $\mu \mathrm{g} / \mathrm{m}^{3}$ ) were measured with a photoionisation detector (PID) (PGM 7240 - RAE Systems) in the living room and carbon dioxide $\left(\mathrm{CO}_{2}\right.$ in $\left.\mathrm{ppm}\right)$ was measured by a non-dispersive infra-red probe (TSI Q-Trak 8552) in the main bedroom. Individual volatile organic compounds (VOC) and aldehydes were collected over seven days in the main bedroom by a passive sampler (Radiello ${ }_{\text {, }}$, and Fondazione Salvatore Maugeri - IRCCS, Italy) with stainless steel net cartridges filled, respectively, with Carbograph 4 adsorbents and with 2,4-dinitrophenylhydrazine (2,4-DNPH)-coated Florisil. Sixteen VOC (1,2,4trimethylbenzene, 1,4-dichlorobenzene, 1-methoxy-2-propanol and its acetate, 2-butoxyethanol and its acetate, benzene, ethylbenzene, m-/p-xylenes, n-decane, n-undecane, o-xylene, styrene, tetrachloroethylene, toluene, trichloroethylene) and four aldehydes (acetaldehyde, acrolein, formaldehyde, hexaldehyde) were quantified in $\mu \mathrm{g} / \mathrm{m}^{3}$ by, respectively, gas chromatography, mass spectrometry and flame ionisation and high-performance liquid chromatography and detection by UV absorption. These 
compounds were measured during the national survey of IAQ in French dwellings [12], and the analytical method and the detection limit for each compound were previously detailed by [16]. Then, all other organic compounds whose concentrations exceeded $1 \mu \mathrm{g} / \mathrm{m}^{3}$ were identified and quantified in $\mu \mathrm{g} / \mathrm{m}^{3}$ toluene equivalent. Carbon monoxide ( $\mathrm{CO}$ in $\mathrm{ppm})$ was monitored only in winter every five minutes during seven days with an electrochemical sensor (Drager Pac III) in each room that contained combustion equipment. The mass concentration of suspended particulate matter with an aerodynamic diameter less than $2.5 \mu \mathrm{m}\left(\mathrm{PM}_{2.5}\right)$ was measured in the living room with a sampling system (Chempass, Model. 3400, Thermo Fisher Scientific) coupled to an air sampler (Microvol 1100, Ecotech) operating at $1.8 \mathrm{l} / \mathrm{min}$ from $5 \mathrm{pm}$ to 8 am on weekdays and for 24 hours a day on weekends. The filters (37-mmdiameter PTFE membrane, 2- $\mu \mathrm{m}$ porosity, Gelman Sciences) were weighed before and after sampling according to NF EN 14907 [17], and mass concentrations are given in $\mu \mathrm{g} / \mathrm{m}^{3}$. During both investigations during occupancy, room temperatures $\left(\mathrm{T}\right.$ in ${ }^{\circ} \mathrm{C}$ ) and relative humidity ( $\mathrm{RH}$ in \%) were monitored every ten minutes with Hydrolog sensors (Rotronic) in the main bedroom and the living room at different heights. Radon concentrations $\left(\mathrm{Bq} / \mathrm{m}^{3}\right)$ were measured over more than two months using two Kodalpha LR 115 detectors (Dosirad, and France), one in the living room and the other in the bedroom, after the inhabitants moved in. The radon measurement was made principally during fall months for houses A, C, E, during spring months for houses D and F and during fall/winter months for house B. During the preoccupancy stage and for normal fan speeds (low, medium, high and sometimes very high) of the MVHR, the $\mathrm{ACH}\left(\right.$ in $\left.^{-1}\right)$ in the main bedroom and living room, the air exhaust rate $(1 / \mathrm{s})$ and the mean noise level (in $\mathrm{dB}(\mathrm{A})$ ) were measured, respectively, by SF6 tracer gas (B \& K Multigas Monitor type 1302 with a B \& K multipoint sampler and doser type 1303), by an array of hot wires (Swemaflow 233, Admi Industries) and by a type-II sonometer (Centre 322). The ACH was measured under the same outdoor conditions. No ACH measurements were made under the MVHR boost fan speed, which was activated for only a short period. The average $\mathrm{ACH}$ of each building was estimated, taking into account the $\mathrm{ACH}$ measurements of both rooms, the volume of those rooms and the total volume of the house. Because doors were opened very often during our investigations and thus homogenous zone of concentration 
created, we supposed that air removal measured in 2 rooms could be translated to the air removal of the whole house. Because the MVHR systems are not very often checked during/after the completion of the building, we decided to evaluate its performance in terms of $\mathrm{ACH}$, air exhaust rate and noise level. Concurrent with sampling and measuring, survey questionnaires were developed based on the national survey on indoor air quality in French dwellings [18] to collect general information on newly constructed houses, their equipment, their occupancy and the activities and perceptions of the inhabitants during each investigation.

\subsection{Graphical representation and statistical analysis}

A histogram representation with vertical error bars was used for measurements of $\mathrm{T}, \mathrm{RH}, \mathrm{PM}_{2.5}$, radon, air exhaust rates and mean noise levels.

The software package SAS 9.1 was used for statistical analysis. To characterise the distribution of the raw data, the following parameters were calculated for the concentrations of $\mathrm{CO}_{2}$ and for the measurements of T and RH: minimum, arithmetic mean, median, maximum and $25^{\text {th }}$ and $75^{\text {th }}$ percentile. For VOC and aldehyde values below the limit of quantification (LQ), the calculated value of the LQ divided by two was used in the statistical calculation (arithmetic mean, median, geometric mean). The differences in indoor environmental parameters $\left(\mathrm{CO}_{2}, \mathrm{~T}\right.$ and $\left.\mathrm{HR}\right)$ between occupancy in summer and in winter for each house were assessed using the Kruskal Wallis rank-sum test. A two-sided test was used because the sign of the difference was not known a priori. Spearman's rank correlation $\left(\mathrm{r}_{\mathrm{s}}\right)$ was used to express correlations between the indoor $\mathrm{PM}_{2.5}$ levels and outdoor $\mathrm{PM}_{2.5}$ levels. P-values $<0.05$ were considered statistically significant.

\section{Results}

\subsection{Performance of MVHR}


The performance of MVHR was evaluated for six houses during the pre-occupancy stage after inspection and their adjustment by the installers; in houses D and E, the systems of ventilation were adjusted after measurement.

\subsubsection{Air exchange per hour (ACH)}

Table 3 presents the measurement of $\mathrm{ACH}\left(\mathrm{in}^{-1}\right.$ ) for the living room and the main bedroom and the average $\mathrm{ACH}$ for the house.

Table 3 - Measured ACH per room and estimation of average $\mathrm{ACH}\left(\mathrm{h}^{-1}\right)$ by house depending on the fan speed of the MVHR system in six houses (confidence interval). n.m.: not measured; n.e.: not estimated

When the MVHR systems were switched off, the ACH of both rooms induced by air leakage did not exceed $0.05 \mathrm{~h}^{-1}$, except in house F, where it reached $0.1 \mathrm{~h}^{-1}$. When the MVHR systems were turned on, the $\mathrm{ACH}$ values increased with increasing fan speed (in houses $\mathrm{A}, \mathrm{B}, \mathrm{D}$ and $\mathrm{F}$ ). The $\mathrm{ACH}$ values ranged between 0.4-0.8 $\mathrm{h}^{-1}$ in house A, 0.2-1.2 $\mathrm{h}^{-1}$ in house $\mathrm{B}, 0.1-1.3 \mathrm{~h}^{-1}$ in house $\mathrm{C}, 0.2-0.7 \mathrm{~h}^{-1}$ in house $\mathrm{D}, 0.2$ $0.6 \mathrm{~h}^{-1}$ in house E and 0.5-0.6 $\mathrm{h}^{-1}$ in house F. Shortcomings appeared at the highest fan speed, where ACH values were in some cases equal to the $\mathrm{ACH}$ value at the medium fan speed (house $\mathrm{C}$ ) or even lower (bedroom of house E). The average ACH values for MVHR systems without a boost fan speed were between 0.1 and $0.3 \mathrm{~h}^{-1}$ at the lower fan speed, 0.3 and $0.5 \mathrm{~h}^{-1}$ at the medium speed and up to $1 \mathrm{~h}^{-1}$ at the highest speed. For the MVHR systems with a boost fan speed (houses A and F), the minimum average $\mathrm{ACH}$ values were $0.6 \mathrm{~h}^{-1}$ and $0.5 \mathrm{~h}^{-1}$, respectively.

\subsubsection{Air exhaust rates}

Air exhaust rates $(1 / \mathrm{s})$ were measured for each outlet and for each fan speed of the MVHR system. For technical reasons (e.g., height, size, geometry of the outlets, presence of furniture fixed to the wall near the outlets), not all measurements were recorded. Figure 2 shows that the air exhaust rates increased with the increasing fan speed of the ventilation systems for the majority of houses, though deviations appear in 
houses A and F. The air exhaust rates were the same for the lower as for the medium fan speed in house A (WC and bathroom 1) and house F (WC and bathroom 2). Finally, for both houses and considering only WC and bathroom outlets, the difference in the air exhaust rates between the lower and the higher fan speeds was smaller (less than $1.7 \mathrm{l} / \mathrm{s}$ ) than in the other houses (between 3.3 and $8.6 \mathrm{l} / \mathrm{s}$ ).

Figure 2 - Measured air exhaust rate (1/s) per room by the fan speed of the MVHR system in six houses

\subsubsection{Average noise level}

The average noise level ( $\mathrm{dB}(\mathrm{A}))$ was measured for each MVHR fan speed. The results are presented in Figure 3, and all measured values less than or equal to $30 \mathrm{~dB}(\mathrm{~A})$ (under the range value of the sonometer used) were replaced by the symbol *. The average noise level increased with increasing MVHR fan speed, except in a few rooms in house F. The utility room where the MVHR system was located was the noisiest (value ranged between 33 and $59 \mathrm{~dB}(\mathrm{~A})$ ), except in house D. The bedrooms (and occasionally office rooms) were generally the quietest (less than 30 to $33 \mathrm{~dB}(\mathrm{~A})$ ), except in houses $\mathrm{B}$ and $\mathrm{D}$ (up to 48 and $36 \mathrm{~dB}(\mathrm{~A})$, respectively). The average noise levels in house E were markedly lower. Overall, indoor noise levels were rated between —qite pleasant" and — etremely pleasant" by the inhabitants. Noises coming from inside the house, especially those from the MVHR ventilator and those that were noticeable at bedtime (B), during the night (A, D) or during quiet parts of the day were rated as more bothersome than noises from outside.

Figure 3 - Measured average noise level (dB(A)) per room depending on the MVHR fan speed in six houses (* average noise level value $\leq 30 \mathrm{~dB}(\mathrm{~A})$ ) (BAT: bathroom; BED: bedroom; LR: living room; OFF: office room; UR: utility room)

\subsubsection{Use of the MVHR system}


During occupancy, several technical improvements were made to the MVHR systems in response to complaints from the inhabitants regarding the poor adjustment of the air-flow rate (houses A and E), disturbance of the air-flow rate during occupancy (houses A and C) or after cleaning the inlets/outlets (house B), noise disturbance (house A and C) and the need to replace components of the ventilation system (houses A and F). The inhabitants reported that the MVHR systems were difficult to use and that the user manual was complex; the majority used only the manual mode rather the program mode. The inhabitants of house E used the program mode, but the available schedules did not match their lifestyle.

\subsection{Indoor environment parameters}

\subsubsection{Air stuffiness and thermal comfort}

The concentrations of $\mathrm{CO}_{2}$ and the $\mathrm{T}$ and $\mathrm{RH}$ values measured in the main bedroom of each house during occupancy (Sum and Win) are presented in Table 4.

Table 4 - Descriptive statistics of $\mathrm{CO}_{2}$ level (ppm), $\mathrm{T}\left({ }^{\circ} \mathrm{C}\right)$ and $\mathrm{RH}(\%)$ measured weekly in the main bedrooms of six occupied houses by season. (Sum: summer; Win: winter; P25: $25^{\text {th }}$ percentile; P75: $75^{\text {th }}$ percentile; n.a.: not available)

The median $\mathrm{CO}_{2}$ levels were always below 1000 ppm and ranged between $351 \mathrm{ppm}$ (house $\mathrm{B}$ ) and 811 ppm (house A). These levels were significantly lower in summer than in winter $(\mathrm{p}<0.0001)$. The lowest levels were close to the measured outdoor level, and the highest levels were less than $2100 \mathrm{ppm}$. Houses $\mathrm{C}$ and $\mathrm{D}$ appeared to have less fresh air than the others because of their high interquartile temperature ranges. The median temperatures were between 20.3 and $25.7^{\circ} \mathrm{C}$ in summer and 19.5 and 21.6 in winter. Larger variation in temperature was observed in winter $\left(8\right.$ to $\left.15^{\circ} \mathrm{C}\right)$ than in summer $\left(3\right.$ to $\left.8{ }^{\circ} \mathrm{C}\right)$. The median RH values were between 45 and 58\% in summer and between 29 and 34\% in winter. As expected, the $\mathrm{T}$ and $\mathrm{RH}$ values were significantly higher in summer than in winter $(\mathrm{p}<0.0001)$. 
According to the inhabitants, the global thermal comfort of their houses ranged between "rather satisfactory" and "satisfactory" in the summer (T and RH were -omfortable") and between "somewhat dissatisfied" and "satisfied" in winter (T was -omfortable", but RH was fairly low). The most discomfort was experienced in winter.

\subsubsection{Indoor air quality}

Table 5 presents the median TVOC levels and the concentrations of the individual VOC and aldehydes measured weekly in the main bedrooms of the seven houses in the pre-occupancy stage and during occupancy.

Table 5- Indoor TVOC, VOC and aldehyde levels $\left(\mu \mathrm{g} / \mathrm{m}^{3}\right)$ measured weekly in seven new low-energy houses at the pre-occupancy stage (Pre) and during occupancy (Sum: summer; Win: winter). LI: Limit of identification $\left(<1 \mu \mathrm{g} / \mathrm{m}^{3}\right)$; LD: limit of detection; LQ: limit of quantification; n.a.: not available; n.m.: not measured; Q.F.: quantification frequency

In the pre-occupancy stage, the median TVOC levels were low in houses A and B (less than $150 \mu \mathrm{g} / \mathrm{m}^{3}$ ) and high in the other houses (between 500 and more that $3000 \mu \mathrm{g} / \mathrm{m}^{3}$ ). In houses C, D and E, the TVOC concentrations were higher in pre-occupancy than during occupancy.

Forty-four VOCs and seven aldehyde compounds in ten families were identified and quantified at least once. The number of these compounds varied between 20 and 35 per house. Seventeen of the 20 targeted compounds measured during the national survey of IAQ in dwellings in France were quantified, and three were never detected (2-butoxy ethyl acetate, 1-methoxy-2-propanol, 1-methoxy-2-propyl acetate). The compounds were split into two groups by quantification frequency: the most frequently detected (in at least $56 \%$ of samples; 14 VOCs: 1,2,4-trimethylbenzene, alkylbenzenes, alpha-pinene, benzene, camphene, n-decane, n-undecane, ethylbenzene, limonene, pentane, styrene, toluene, m- and p-xylene, and o-xylene; five aldehydes: acetaldehyde, acrolein, formaldehyde, hexaldehyde and isovaleraldehyde) and the least frequently detected (in at most $39 \%$ of samples; 30 VOCs and two aldehydes). For the most frequently detected compounds, high levels were measured in the pre-occupancy stage in houses C, E and 
G and lower levels were measured in house A. During occupancy, eight compounds were always quantified. Hexaldehyde presented the highest concentrations in the majority of houses both before occupancy $\left(69.7-856 \mu \mathrm{g} / \mathrm{m}^{3}\right)$ and after $\left(36.1-104.9 \mu \mathrm{g} / \mathrm{m}^{3}\right.$ in summer and 14.6-96 $\mu \mathrm{g} / \mathrm{m}^{3}$ in winter). Formaldehyde was the only compound whose concentrations were systematically higher in summer than winter. Acetaldehyde, n-decane, n-undecane, alpha- pinene, 1,2,4-trimethylbenzene and o-xylene were also always measured. For the less frequently measured compounds, high levels were detected in the preoccupancy stage in houses $\mathrm{C}$ and $\mathrm{E}$. N-butyl acetate was quantified at high concentrations in only two buildings (548.1 $\mu \mathrm{g} / \mathrm{m}^{3}$ in occupied house $\mathrm{B}$ in winter and $108.2 \mathrm{in} \mu \mathrm{g} / \mathrm{m}^{3}$ in unoccupied house E). This compound is mainly used as a solvent or diluent in the cosmetics, clothing, automotive, food and pharmaceutical industries and in the production of liquid floor wax, photographic film and plastics [19] Here, this compound may be related to the use of perfume and/or cosmetics such as nail polish and nailpolish remover [20] because VOC sampling was carried out in the main bedrooms opening onto a private bathroom. In house B, the inhabitants declared daily use of perfume and hairspray during the week of measurement in winter. In house E, the inhabitants lived in the house during the two first days of the preoccupancy stage, when the MVHR system was switched off.

The mass concentrations of $\mathrm{PM}_{2,5}$ were always below $30 \mu \mathrm{g} / \mathrm{m}^{3}$ and ranged from 6 (house $\mathrm{C}$ ) to $28 \mu \mathrm{g} / \mathrm{m}^{3}$ (house B; Figure 4). The measured concentrations were higher in winter than in summer in houses A, B, $\mathrm{C}$ and $\mathrm{E}$ but not in house $\mathrm{F}$. This exception can be linked to the proximity of a construction site to house $\mathrm{F}$ during the summer. For all houses, the pre-occupancy concentrations of $\mathrm{PM}_{2,5}$ remained under $15 \mu \mathrm{g} / \mathrm{m}^{3}$ and never exceeded those levels during occupancy. The radon concentrations ranged between 7 and 66 $\mathrm{Bq} / \mathrm{m}^{3}$ and were highest in houses $\mathrm{B}$ and $\mathrm{E}$ and lowest in house $\mathrm{D}$ (Figure 5). In general, the radon concentrations were higher in the living room than in the main bedroom, except in house E. CO concentrations were measured during the winter in only three houses (B, D and E), all of which had wood stoves, and were near zero ppm, with a peak at 8 ppm measured immediately after lighting the wood stove in house D. 
Figure 4 - Weekly mass concentrations of $\mathrm{PM}_{2.5}\left(\mu \mathrm{g} / \mathrm{m}^{3}\right)$ measured in the living room for six houses during the pre-occupancy stage (Pre) and during occupancy (summer: Sum; winter: Win). n.a.: not available; n.m.: not measured

Figure 5 - Radon concentrations $\left(\mathrm{Bq} / \mathrm{m}^{3}\right)$ measured in the living room and in the main bedroom for six occupied houses. n.a.: not available

\section{Discussion}

\subsection{Assessment of the performance and the use of MVHR}

When the MVHR systems were switched off, the ACH of most of houses was less than $0.05 \mathrm{~h}^{-1}$ (except

for house $\mathrm{F}$, at $0.12 \mathrm{~h}^{-1}$ ), confirming that the buildings were highly airtight (as previously measured with a blower-door test). The average ACH generated by four adjusted MVHR systems before measurement (houses A, B, C and F) at the medium (most used) fan speed was compared to a rate of $0.5 \mathrm{~h}^{-1}$. This value corresponds to the median ACH value of French dwellings [13] and is frequently used in national standards/regulation in Europe [21]. A value of $0.5 \mathrm{~h}^{-1}$ was reached in houses B, C and $\mathrm{F}$ and exceeded in house A. The measured air exhaust rates for four adjusted MVHR systems before measurement (houses A, B, C and F) were compared to the French regulations concerning residential-building ventilation [14]. It appears that the achievable air exhaust rates and the minimum values of reduced rates were reached occasionally but not systematically for each house (Table 6). The average noise levels in the main bedrooms of the four houses were near $30 \mathrm{~dB}(\mathrm{~A})$ for the low fan speed). For the other fan speeds, higher noise levels (between 35 and $48 \mathrm{~dB}(\mathrm{~A})$ ) caused the inhabitants to complain, as in house B. Our observations were consistent with those of eight passive houses [22] and in recently built Dutch homes equipped with MVHR systems and natural and mechanical-exhaust ventilation [23]. Shortcomings such as insufficient ventilation, high noise levels, unclean systems and insufficient maintenance were common [23]. The recurring problem in MVHR-ventilated airtight buildings is not a technical shortcoming of the ventilation system itself; installer expertise and solid installation-qualification procedures are 
indispensable to MVHR success [24]. Finally, the inhabitants in our study found the ventilation system difficult to use, as previously shown in passive houses [25].

Table 6 - Comparison of the measured air exhaust rate $(1 / \mathrm{s})$ for four houses to the French regulations concerning residential-building ventilation [14].

\subsection{Comparison of our IAQ results to those of previous studies}

During the pre-occupancy stage, the instructions were as follows: absence of inhabitants, selection of the median fan speed for the MVHR system and no air-polluting activities such as painting, aerosol spraying and sanding. These instructions were followed in all but not for three houses: there was painting in house $\mathrm{C}$, the presence of inhabitants during the first 24 hours and painting in house $\mathrm{E}$ and the MVHR systems were switched off in houses E and G. Thus, the highest concentrations of the most common VOCs and aldehydes were measured in those houses, although the mass concentrations of $\mathrm{PM}_{2.5}$ were unchanged. The lowest concentrations were observed in house A, for which the estimated average $\mathrm{ACH}$ for the medium MVHR fan speed was nearly double $\left(0.9 \mathrm{~h}^{-1}\right)$ that of the other houses (approximately 0.5 $\mathrm{h}^{-1}$ ). Moreover, this house was investigated 13 months after its completion versus one month for the other houses. The geometric concentrations of TVOC and of the most commonly quantified VOCs and aldehydes of three unoccupied houses for which the instructions were followed (houses A, B and D) were calculated. VOCs and aldehydes were compared to data from previous studies. Our TVOC values obtained with a PID instrument and providing information on a given mixture of VOC cannot be compared with TVOC values obtained in other studies by using sampling on a sorbent and subsequent separation by gas chromatography. Those studies were conducted in unoccupied and ventilated dwellings less than one year old, which can be energy efficient (EE) and/or built with low-emissions material (LE) (Table 7). It appears that the concentrations of TVOC and the majority of aromatic hydrocarbons measured in our study were consistently lower than those reported by authors from other countries. The concentrations of other organic compounds were also always lower than those reported [26,27,28]. 
However, the concentrations of aldehydes, terpenes, aliphatic hydrocarbons and 1,2,4-trimethylbenzene were sometimes higher than those measured [10,29,30,31,32,33]. The concentrations of organic compounds measured in non-ventilated houses $(\mathrm{E}$ and $\mathrm{G})$ were higher than those reported in a new, unventilated Minergie home [8], except for alpha-pinene, formaldehyde and acetaldehyde.

Table 7 - Comparison of geometric concentrations of TVOC and of the most frequently quantified VOC and aldehydes in this study in three unoccupied houses (A, B and D) to the results of previous studies conducted in unoccupied and ventilated dwellings less than one year old. Some of these houses may have been energy-efficient and/or built with low-emitting material. n.m.: not measured

The arithmetic means of TVOC and the geometric means of the most frequently measured VOCs and aldehydes in occupied houses (A, B, C, D, E and F) in summer and in winter were compared (Table 8) to data from previous studies. Those studies were conducted in newly occupied homes and presented in a recent literature review [34]. Only studies conducted in occupied and ventilated dwellings less than one year old were selected, and a small number of studies in energy-efficient homes were added. Our TVOC concentrations were lower than those reported in 24 R-2000 standard homes in Canada [35], in two Minergie apartments in Switzerland [8] and in 292 dwellings in Japan [36]. Our results were similar to those measured in six apartments built with low-emissions material in Finland [30]. The decrease in TVOC levels over time observed in houses C, D and E was also reported by other authors [35]. In R-2000 standard homes, TVOC concentrations were higher during the first week after closure and then decreased with time and became relatively stable approximately 40 days after closure, at approximately one quarter of the maximum observed level [6]. A 50\% decrease in TVOC levels was observed after seven days of strong ventilation [30]. All VOCs and aldehydes measured in our study presented concentrations lower than those reported by another authors [36,37]. The concentrations of ethylbenzene, styrene, toluene and limonene measured in our study were lower than those reported by any other study. For all other compounds, the concentrations were in the ranges of those measured in another studies $[10,11,30,35]$.

Table 8 - Comparison of the mean concentration of TVOC and geometric mean concentrations of the most frequently VOC and aldehydes quantified in this study in six occupied houses (A, B, C, D, E and F) in summer and winter with the results of previous studies conducted in newly occupied and ventilated 
dwellings less than one year old. Some of these houses may have been energy-efficient and/or built with low-emissions material. n.m.: not measured

\subsection{Comparison of our IAQ results to the standard French houses $F$ and the indoor air-quality guideline values used in France}

The values of $\mathrm{CO}_{2}$, VOC, aldehyde compounds, $\mathrm{PM}_{2.5}$ mass, radon concentrations, temperature and relative humidity in the occupied houses $(\mathrm{A}, \mathrm{B}, \mathrm{C}, \mathrm{D}, \mathrm{E}$ and $\mathrm{F})$ were compared to the IAQ of the standard French houses [12]. The standard French houses have an $\mathrm{ACH}$ of $0.5 \mathrm{~h}^{-1}$ [13] but are older than the houses in our study (half built before 1968), are under-equipped with MVHR (only 1.1\%), are built predominantly of masonry (only $6 \%$ wood frame), have higher occupation rates $(0.8)$ and allow smoking (34\% of homes have at least one smoker).

The median $\mathrm{CO}_{2}$ concentrations measured in summer and in winter in our study were lower than the national median $\mathrm{CO}_{2}$ level (756 ppm) for three houses (B, E and F) and between $756 \mathrm{ppm}$ and $1000 \mathrm{ppm}$ for the other houses (A, C and D). The seasonal variation in $\mathrm{CO}_{2}$ levels (lower in summer than in winter) is most likely related to the increased rate of air exchange in these houses in summer due to the opening of windows, as observed in another studies $[38,39]$. The occupants of our houses reported opening the windows more than one half hour per day in summer and rarely or almost never in winter, as in standard French houses [13], suggesting that the occupants of low-energy houses do not drastically change their usual ventilation behaviours. The comparison between the median temperatures and relative humidities measured in these houses and the median values of French dwellings are shown in Figure 6. Houses A, B and $\mathrm{F}$, but not houses $\mathrm{C}, \mathrm{D}$ and $\mathrm{E}$, exceeded the national median temperature. In contrast, only house $\mathrm{E}$ reached the national median relative humidity, specifically in winter.

Figure 6 - Comparison of weekly median $\mathrm{T}\left({ }^{\circ} \mathrm{C}\right)$ and $\mathrm{RH}(\%)$ measured in the bedroom for six occupied houses (Sum: summer; Win: winter) to the seasonal values measured in standard French dwellings (CNL). n.a.: not available 
The median ratios of the average concentrations of $\mathrm{VOC}$, aldehydes, $\mathrm{PM}_{2.5}$ and radon measured in all occupied houses to the national median concentration in standard French dwellings are presented in Figure 7. Compared to the median concentration of indoor air pollutants in standard French dwellings, the average concentrations of $\mathrm{PM}_{2.5}$, radon and two aromatic hydrocarbons compounds (benzene and toluene) were lower, whereas the concentration of formaldehyde was not significantly different. The concentrations of three aromatic hydrocarbon compounds (ethylbenzene, m- and p-xylene and 1,2,4trimethylbenzene), one aldehyde (acrolein) and one aliphatic hydrocarbon compound (n-decane) were less than 1.5 times higher than the national levels. Other compounds were more markedly elevated in concentration, including hexaldehyde (up to 4.7 times higher) and n-decane (up to two times higher) and (to a lesser extent) styrene, o-xylene and acetaldehyde (between 1.7 and 1.5 times higher).

Figure 7 - Median ratio of the average concentrations of VOC, aldehydes, $\mathrm{PM}_{2.5}$ and radon measured in six occupied houses to the national median concentration in French dwellings

Although it is difficult to explain these differences, the high levels of hexaldehyde may be associated with the use of wood as the main construction material [27]. The degradation of the wood (composite wood products and lumber) or its secondary metabolites is most likely responsible for the presence of the aldehydes [40]. High aldehyde levels may also be related to the use of paints and varnishes for wood $[41,42,43]$, the presence of new materials (less than one year old) such as particle-board furniture [44] and the surface coverings of walls [45], floors and ceilings [46]. The recent use of products containing solvents (paint, adhesives, etc.) may cause elevated concentrations of n-undecane and n-decane [47]. Formaldehyde was present in homes in our study at levels comparable to other French homes, although higher levels were expected because of the age of the buildings and materials (less than one year) and the high use of wood. The low concentration of radon and the low mass concentration of $\mathrm{PM}_{2.5}$ may be associated with the very high airtightness of these buildings compared to average French homes. Based on the living room's radon measurement (on ground level), the mean concentration reaches $16 \mathrm{~Bq} / \mathrm{m}^{3}$ for measurement period in spring, $35 \mathrm{~Bq} / \mathrm{m}^{3}$ for measurement period in fall. The only one measure available for measurement period in fall/winter is equal to $43 \mathrm{~Bq} / \mathrm{m}^{3}$ (for house $\mathrm{B}$ ). According this observation, 
occupants' window opening behaviour depending on season could have an impact on radon concentration but this hypothesis can't be validated because their behaviours haven't been recorded during the radon measurement period. Finally, the low concentrations of aromatic hydrocarbons may be related to the general absence of attached garages, which are known to be an important source of those compounds $[48,49,50]$. The high concentrations of benzene and toluene in house A, the only building with an attached garage, seem to reinforce this hypothesis. The drier air might be associated with better ventilation in houses equipped with MVHR systems [51] and with a lower production of water vapour because of the under-occupation of these buildings.

The concentrations of formaldehyde, benzene and radon did not exceed the indoor air-quality guideline values currently used in France (respectively $30 \mu \mathrm{g} / \mathrm{m}^{3}$ long-term exposure, $1^{\text {st }}$ January $2015,5 \mu \mathrm{g} / \mathrm{m}^{3}$ long-term exposure, $1^{\text {st }}$ January 2013 [52] and $400 \mathrm{~Bq} / \mathrm{m}^{3}$ for a public building according [53]). The concentrations of acetaldehyde, xylenes, styrene and toluene were within the European guideline values [54] (respectively $200 \mu \mathrm{g} / \mathrm{m}^{3}, 200 \mu \mathrm{g} / \mathrm{m}^{3} 250 \mu \mathrm{g} / \mathrm{m}^{3}$ and $300 \mu \mathrm{g} / \mathrm{m} 3$ ), but the level of $\mathrm{PM}_{2.5}$ exceeded the WHO air-quality guidelines [55] (10 $\mu \mathrm{g} / \mathrm{m}^{3}$ annual mean).

\subsection{Temporal variation of IAQ in occupied houses}

The temporal variation in IAQ in the six occupied houses was calculated based on the concentration ratio between the measurements made during the first and second surveys for $\mathrm{PM}_{2.5}$ and VOC and aldehyde compounds in at least four houses (Figure 8). For VOC and aldehydes, the ratios were calculated only for each compound measured in each survey. The first survey was conducted in summer and the second in winter, except for houses D and F. The interval between the surveys was three months for house D, four months for house $\mathrm{C}$ and six months for houses $\mathrm{A}, \mathrm{B}, \mathrm{E}$ and $\mathrm{F}$. The median of the ratios for each of the six houses was calculated.

Figure 8 - Ratio of the concentrations of VOC, aldehydes and $\mathrm{PM}_{2.5}$ measured during the second survey to those measured during the first survey for each of six occupied houses and ratio of the median concentrations for all houses 
The majority of VOC and aldehydes exhibited lower concentrations in the second survey (median ratio less than 1), or similar in the case of 1,2,4-trimethylbenzene, whereas the opposite trend was observed for n-undecane and $\mathrm{PM}_{2.5}$ (median ratio greater than 1).

The concentrations of toluene, styrene, xylenes, ethylbenzene, terpenes (alpha-pinene and limonene) and acetaldehyde decreased for most of the houses, suggesting that these compounds were mainly emitted by building sources such as building material, insulation, decoration, surface coatings, furniture and other sources. The concentrations of these compounds decreased with the decreasing of emission-source strength over time. Those observations were consistent with another authors [35], which showed significantly reduced concentrations of styrene, p-xylene and alpha pinene over one year in new homes. Another authors [37] also observed over a period of one year in a wood detached house that concentrations of seven COV compounds, including toluene, alpha-pinene and limonene, exhibited a declining trend with time. Several authors have shown that aldehyde concentrations can be influenced by building materials and human activities [30,44]. In our study and because of the recent construction of the buildings, building materials appear to have been the principal source of high aldehyde concentrations $[45,46]$. The decreased hexaldehyde concentrations may be correlated with the increased age of the furniture and the ground/wall/ceiling coverings [46], but after more than one year, none of these materials has any influence on hexaldehyde levels [44]. In houses D and F, the higher levels of formaldehyde observed during the second survey (in summer) corroborated the observations of other authors [31,56,57]. This increase may be attributed principally to the influence of temperature on VOC emissions from materials [58] and secondarily to the reactions between organic compounds (especially terpenes) and ozone $[59,60,61]$. A study carried out in new single - family homes in California showed that as outdoor air exchange rates decrease or the indoor temperature increases, the indoor concentrations of formaldehyde increase [62].

The highest concentrations of benzene and toluene relative to national standards were observed in house A (ratios of 3.9 and 1.3, respectively) and seem to be linked to the presence of an attached garage. Several 
authors $[48,49,50]$ have shown that many pollutant sources, such as gasoline-fired engines (automobiles, gardening tools such as lawnmowers, etc.), fuel, paint and solvent are commonly stored or used in residential attached garages and may be an important source of monocyclic aromatic hydrocarbons.

The high ratios of n-undecane concentrations relative to national standards in houses A, B and E (1.9, 7.0 and 4.6, respectively; attributable to painting that occurred in houses B and E between the two surveys) explained the high median ratio level observed for all houses (median ratio $=1.3$ ). The relatively high levels of $n$-decane in houses B and E (ratios of 4.7 and 2.1, respectively) support this hypothesis.

Increased concentrations of $\mathrm{PM}_{2.5}$ (median = 1.8) were observed in all buildings except house $\mathrm{F}$ and seem to be seasonal. The influence of season on the particulate-matter concentrations has previously been reported $[63,64]$ and appears to be linked to different ventilation practices in summer and winter. According to a meta-analysis conducted in Europe [65], the highest particulate-matter infiltration was observed in summer, with the lowest infiltration in winter. Because of the increased ventilation in summer from the opening of windows, indoor PM levels were highly correlated with outdoor PM levels, whereas in winter, PM levels were more strongly influenced by human indoor activities. In our study, indoor and outdoor $\mathrm{PM}_{2.5}$ concentrations showed a strong positive correlation in summer $(\mathrm{r}=0.98)$ and a weak positive correlation in winter $(\mathrm{r}=0.11)$. Finally, the highest ratio of $\mathrm{PM}_{2.5}$ concentrations, observed in houses $\mathrm{B}$ and $\mathrm{E}(\geq 3)$, seems to be related to the use of wood for heating during the second survey (in winter). The impact of the wood heating system on indoor $\mathrm{PM}_{10}, \mathrm{PM}_{2.5}$ and $\mathrm{PM}_{1}$ concentrations has been shown previously [66].

\section{Conclusions}

Seven newly built, low-energy single-family detached houses in France conform to the highly airtight and energy-efficient standards set forth in RT2012 were investigated during the pre-occupancy stage and during occupancy in summer and winter. Because of the limited sample size, caution must be taken and 
the findings can't be generalized. The following conclusions can be drawn from the present study but contribute significantly to knowledge about IAQ and occupant's comfort in energy efficient homes.

Several IAQ-indicator measurements show that the concentrations of aromatic hydrocarbons, terpenes, alkanes and aldehydes were higher in the pre-occupancy stage than during occupancy. The concentrations of some aromatic hydrocarbons (toluene, ethylbenzene, xylenes, styrene), terpenes (alpha-pinene, limonene) and acetaldehyde decreased with time, possibly in relation to the decrease in emissions from building materials over time. The concentrations of alkanes (n-decane and n-undecane), benzene and major aldehydes (formaldehyde and hexaldehyde) may increase temporarily in response to human activities. The $\mathrm{PM}_{2.5}$ levels increased during occupancy and appear to be related, in summer, to the outdoor $\mathrm{PM}_{2.5}$ levels via an increased infiltration level and with indoor human activities in winter. The air temperature and relative humidity were higher in summer than in winter (between 20 and $26{ }^{\circ} \mathrm{C}$ in summer, versus between 20 and $22{ }^{\circ} \mathrm{C}$ in winter between 45 and $58 \% \mathrm{RH}$ versus 29 and $34 \% \mathrm{RH}$, respectively).

Compared to the IAQ of standard French houses, the median concentrations of $\mathrm{PM}_{2.5}$, radon, benzene and toluene were lower in the houses studied. The air temperature and the formaldehyde concentrations were similar to those found in typical French houses, whereas the concentrations of ethylbenzene, m- and pxylene, 1,2,4-trimethylbenzene and acrolein were slightly higher (less than 1.5-fold). In contrast, concentrations of hexaldehyde, acetaldehyde, styrene, o-xylene, n-decane and n-undecane exceeded the levels in typical French dwellings by more than $50 \%$. The concentrations of these compounds seem to be related to new construction. The relative humidity of the study houses was lower than in French dwellings, possibly due to the constant and permanent ventilation occurred by the MVHR systems and due to limited water production linked to the under-occupancy of the study houses. The levels of indoor pollutants in the study houses were within the guideline values for indoor air quality used in France, but the $\mathrm{PM}_{2.5}$ level exceeded the levels set by WHO recommendations. The MVHR systems exhibited commonly reported shortcomings but provided sufficient ACH ( $\geq 0.5$ h-1). In summer, the inhabitants improved the houses' ventilation by opening windows, as in conventional dwellings. MVHR systems 
seem to be difficult to use, and high noise levels can be produced at the highest fan speed. Finally, in airtight buildings, the mechanical ventilation systems must work constantly; if they shut down, without ventilation through open windows, indoor air quality can be become poor and present a risk to human health.

\section{Acknowledgements}

This study was supported by the Scientific and Technical Building Centre (CSTB) through the lead author's research programme and by the French Observatory of Indoor Air Quality (OQAI), which is funded by the Ministries of Housing, Environment and Health; the Environment and Energy Management Agency (ADEME); the French agency for Food, Environmental and Occupational Health Safety (ANSES); and the CSTB. The authors thank the owners and the tenants of the study houses for their time and for opening their homes for this study. Sample analyses were conducted by three laboratories (Paris Hygiene Laboratory for $\mathrm{PM}_{2.5}$ concentrations, chemical laboratory of CSTB for the VOC and aldehyde analyses, Dosirad for radon measurements).

\section{References}

[1] Grenelle de l'Environnement. Lutter contre les changements climatiques et maîtriser l'énergie Rapport de synthèse du Groupe 1. 2008.

[2] ADEME. Les chiffres clés du bâtiment Énergie-Environnement : Edition 2011, 2012.

[3] Loi Grenelle 1. Loi n ${ }^{\circ} 2009-967$ du 3 août 2009 de programmation relative à la mise en œuvre du Grenelle de l'environnement (1). JORF n 179 du 5 août 2009, p 13031. 
[4] Crump D, Dengel A and Swainson M. Indoor air quality in highly energy efficient homes - a review. NHBC Foundation report NF18, Published by IHS BRE Press on behalf of the NHBC Foundation, ISBN: 978-1-84806-104-0, 2009.

[5] Feist W, Werner J. Ventilation concept, indoor air quality and measurement results in the "Passivhaus Kranichstein". Proceeding of the 15th AIVC Conference, Buxton, Great Britain, 1994; 1: 321-32.

[6] Shaw CY, Magee RJ, Swinton MC, Riley M, Robar J. Canadian experience in healthy housing. International symposium on current status of indoor air pollution by organic compounds and countermeasures for healthy housing, Tokyo, Japan, 2001:31-35.

[7] Wendt R, Aglan H, Livengood S, Khan M, Ibrahim, E. Indoor Air Quality of an Energy-Efficient, Healthy House with Mechanically Induced Fresh Air. ASHRAE 2004 Annual Meeting, Nashville,110,2: $1-8$.

[8] Dalang F, Bianco MA. Pour un air sain dans des bâtiments durables, Pollution intérieure dans trois maisons familiales, étude pilote pour la surveillance de la qualité de l'air dans des habitations. Rapport Service cantonal de toxicologie industrielle et de protection contre les pollutions intérieures, 2006.

[9] Moriske HJ, Wensing M. Untersuchungen zur raumlufthygienischen Situation in energetisch sanierten Altbauten und in einem Passivhaus. Gefahrst Reinhalt L 2007; 67(3):85-90.

[10] Dalang F. La qualité de l'air intérieur dans les logements du quartier du Pommier, Résultats d'une campagne de surveillance de la qualité de l'air intérieur 2004 et 2005. Rapport Service cantonal de toxicologie industrielle et de protection contre les pollutions intérieures, 2007.

[11] Engelmann P, Roth K, Tiefenbeck V. Comfort, indoor air quality, and energy consumption in low energy homes, NREL Report No. SR-5500-56023; DOE/GO-102013-3746, 2013. 
[12] Kirchner S, Arènes JF, Cochet C, Derbez M, Duboudin C, Elias P et al. État de la qualité de l'air dans les logements français. Environ Risque Sante 2007; 6(4):259-69.

[13] Lucas JP, Ramalho O, Kirchner S, Ribéron J. Etat de la ventilation dans le parc de logements français, CSTB, report N DESE/SB-2009-37; 2009.

[14] Arrêté du 24 mars 1982 modifié par l'arrêté du 28 octobre 1983 (JORF du 15 novembre 1983) relatif à l'aération des logements: aération générale ou permanente, aération permanente pouvant être limitée à certaines pièces. JORF du 27 mars 1989, p942

[15] Derbez M, Berthineau B, Cochet V, Lethrosne M, Pignon C, Ribéron J, Kirchner S. Méthodologie d'évaluation de la qualité de l'air intérieur, du confort des occupants et des consommations énergétiques réelles des bâtiments d'habitation performants en énergie. Environ Risque Sante 2012;11(1): 40-51.

[16] Ramalho O, Derbez M, Grégoire A, Garrigue J, Kirchner S. French permanent survey on Indoor Air Quality - Part. 1 : Measurement protocols and quality control. Proceedings of the 8th International Conference of Healthy Buildings, Lisbon, Portugal. 2006; vol 3: 321-26.

[17] AFNOR. Ambient air quality - Standard gravimetric measurement method for the determination of the $\mathrm{PM}_{2,5}$ mass fraction of suspended particulate matter (AFNOR standard NF EN 14907); 2006.

[18] Derbez M, Grégoire A, Ramalho O, Garrigue J, Kirchner S. French permanent survey on Indoor Air Quality : Part. 2 : Questionnaires and validation procedure of collected data. Proceedings of the 8th International Conference of Healthy Buildings, Lisbon, Portugal. 2006;3:327-32.

[19] Health Council of the Netherlands: Dutch Expert Committee on Occupational Standards. n-, iso-, sec-, and tert-Butyl acetate; Health-based recommended occupational exposure limit. The Hague: Health Council of the Netherlands, 2001; publication no. 2001/03OSH. 
[20] Toy NJ. Final report on the safety assessment of ethyl acetate and butyl acetate. J Am Coll Toxicol 1989;8: 681-705.

[21] Dimitroulopoulou C. Ventilation in European dwellings: A review. Build Environ 2012;47:109-25.

[22] Larsen TS, Jensen RL, Daniels O. The Comfort Houses. Measurements and analysis of the indoor environment and energy consumption in 8 passive houses 2008-2011. DCE Technical report N 145. ISSN 1901-726X, 2012.

[23] Balvers J, Bogers R, Jongeneel R, van Kamp I, Boerstra A, van Dijken F. Mechanical ventilation in recently built Dutch homes: technical shortcomings, possibilities for improvement, perceived indoor, environment and health effects. Architect Sci Rev 2012;55(1): 4-14.

[24] Van der Pluijm WMP. The robustness and effectiveness of mechanical ventilation in airtight dwellings. A study to the residential application of mechanical ventilation with heat recovery in the Netherlands. Eindhoven University of Technology, Master's Thesis; 2010.

[25] Hasselaar E. Health risk associated with passive houses : an exploration. Proceedings of the $11^{\text {th }}$ international Conference on Indoor Air Quality and Climate, Copenhagen, Denmark, 2008: paper ID 689.

[26] Crump D, Squire R, Yu C. Sources and Concentrations of Formaldehyde and Other Volatile Organic Compounds in the Indoor Air of Four Newly Built Unoccupied Test Houses. Indoor Built Environ $1997 ; 6: 45-55$.

[27] Hodgson AT, Beal D, McIllaine JER. Sources of formaldehyde, other aldehydes and terpenes in a new manufactured house. Indoor Air 2002;12:235-42.

[28] Hodgson AT, Rudd AF, Beal D, Chandra S. Volatile organic compound concentrations and emission rates in new manufactured and site-built houses. Indoor Air 2000;10:178-92. 
[29] Brown SK. Volatile organic pollutants in new and established buildings in Melbourne, Australia. Indoor Air 2002;12(1):55-63.

[30] Tuomainen M, Pasanen AL, Tuomainen A, Liesivuoria J, Juvonend P. Usefulness of the Finnish classification of indoor climate, construction and finishing materials: comparison of indoor climate between two new blocks of flats in Finland. Atmos Environ 2001;35(2):305-13.

[31] Järnström H, Saarela K, Kalliokoski P, Pasanen AL. Reference values for indoor air pollutant concentrations in new, residential buildings in Finland. Atmos Environ 2006;40(37):7178-91.

[32] Lim S, Lee K, Seo S, Jang S. Impact of regulation on indoor volatile organic compounds in new unoccupied apartment in Korea. Atmos Environ 2011;45(11):1994-2000.

[33] Kim SS, Kang DH, Choi DH, Yeo MS, Kim KW. Comparison of strategies to improve indoor air quality at the pre-occupancy stage in new apartment buildings. Build Environ 2008;43(3):320-8.

[34] Mandin C, Maupetit F. Qualité de l'air intérieur dans les bâtiments neufs : données disponibles et spécificités. Pollution Atmospherique 2011;209:47-56.

[35] Park JS, Ikeda K. Variations of formaldehyde and VOC levels during 3 years in new and older homes. Indoor Air 2006;16(2):129-35.

[36] Gusdorf J., Parekh A. Energy efficiency and Indoor air quality in R-2000 and conventional new houses in Canada, Proceedings of the 11th biennial Summer Study on Energy Efficiency in Buildings, Pacific Grove, USA. 2000,1.101-1.112.

[37] Yamaguchi T, Nakajima D, Ezoe Y, Fujimaki H, Shimada Y, Kozawa K et al. Measurement of volatile organic compounds (VOCs) in new residential buildings and VOCs behavior over time, $\mathrm{J}$ UOEH.2006; 28(1):13-27. 
[38] Wallace L, Emmerich SJ, Howard-Reed C. Continuous measurements of air change rates in an occupied house for 1 year : the effect of temperature, wind, fans, and windows. J Expo Sci Environ Epidemiol 2002;12:296-306.

[39] Howard-Reed C, Wallace LA, Ott WR. The effect of opening windows on air change rates in two homes. J Air Waste Manage 2002;52:147-59.

[40] Baumann MGD, Lorenz LE, Batterman S.A. Aldehyde emissions from particleboard and medium density fiberboard products. Forest Prod J 2000;50(9):75-82.

[41] Afshari A, Lundgren B, Ekberg LE. Comparison of three small chamber test methods for the measurement of VOC emission rates from paint. Indoor Air 2003;13(2):156-65.

[42] Chang JCS, Guo Z. Emissions of odorous aldehydes from alkyd paint. Atmos Environ 1998;32: 3581-6.

[43] Fortmann R, Roache N, Chang JCS, Guo Z. Characterization of emissions of volatile organic compounds from interior alkyd paint. J Air Waste Manage 1998;48(10):931-40.

[44] Dassonville C, Demattei C, Laurent AM, Le Moullec Y, Seta1 N, Momas I. Assessment and predictor determination of indoor aldehyde levels in Paris newborn babies' homes. Indoor Air 2009;19 (4):314-23.

[45] Clarisse B, Laurent AM, Seta N, Le Moullec Y, Hasnaoui A El, Momas I. Indoor aldehydes: measurement of contamination levels and identification of their determinants in Paris dwellings. Environ Res 2003;92:245-53.

[46] Marchand C, Le Calve S, Mirabel P, Glasser N, Casset A, Schneider N. et al. Concentrations and determinants of gaseous aldehydes in 162 homes in Strasbourg (France). Atmos Environ. 2008;42:50516. 
[47] Brown SK, Sim MR, Abramson MJ, Gray CN. Concentrations of Volatile Organic Compounds in Indoor Air - A Review. Indoor Air 1994; 4:123-34.

[48] Graham LA, Noseworthy L, Fugler D, O'Leary K, Karman D, Grande C. Contribution of vehicle emissions from an attached garage to residential indoor air pollution levels. J Air Waste Manage 2004;54 (5):563-84.

[49] Batterman S, Hatzivasilis G, Jia C. Concentrations and emissions of gasoline and other vapors from residential vehicle garage. Atmos Environ 2006;40: 1828-44.

[50] Dodson RE, Levy JI, Spengler JD, Shine JP, Bennett DH. Influence of basements, garages, and common hallways on indoor residential volatile organic compound concentrations. Atmos Environ 2008;42:1569-81.

[51] Howieson SG, Lawson A, McSharry C, Morris G, McKenzie E, Jackson J. Domestic ventilation rates, indoor humidity and dust mite allergens - Are our homes causing the asthma pandemic. Build Serv Eng Res Technol 2003;24(3):137-47.

[52] Décret n 2011-1727 du 2 décembre 2011 relatif aux valeurs-guides pour l'air intérieur pour le formaldéhyde et le benzène, JORF N0281 du 4 décembre 2011 page 20529.

[53] Arrêté du 22 juillet 2004 relatif aux modalités de gestion du risque lié au radon dans les lieux ouverts au public. JORF $\mathrm{N}^{\circ} 185$ du 11 aout 2004, page 14359.

[54] European Commission, JRC. The INDEX Project: Summary of recommendations and management options, December 2004.

[55] WHO. Air quality guidelines. Global update 2005. Particulate matter, ozone, nitrogen dioxide and sulfur dioxide, Copenhagen, WHO Regional Office for Europe, ISBN 978928902192 0, 2006 
[56] Reponen T, Raunemaa T, Savolainen T, Kalliokoski P. The effect of material ageing and season on formaldehyde levels in different ventilation systems. Environ Int 1991;17:349-55.

[57] Raw GJ, Coward SKD, Brown VM, Crump DR. Exposure to air pollutants in English homes. J Expo Sci Environ Epidemiol 2004;14:85-94.

[58] Wolkoff P. Impact of air velocity, temperature, humidity and air on long-term VOC emissions from building products. Atmos Environ 1998;32:2659-68.

[59] Weschler CJ, Schields HC. Potential reactions among indoor air pollutants. Atmos Environ 1997;31:3487-95.

[60] Weschler CJ, Clausen PA, Wilkins CK, Nielsen GD. Formation of strong airway irritants in terpene/ozone mixtures. Indoor Air 2000;10:82-91.

[61] Weschler CJ. Ozone in indoor environments: concentration and chemistry. Indoor Air 2000;10:26988.

[62] Offermann FJ. Ventilation and Indoor Air Quality in New Homes. California Air Resources Board and California Energy Commission, PIER Energy - Related Environmental Research Program. Collaborative Report. CEC - 500 - 2009 - 085. 2009.

[63] Fromme H, Twardella D, Dietrich S, Heitmann D, Schierl R, Liebl B et al.. Particulate matter in the indoor air of classrooms - exploratory results from Munich and surrounding area. Atmos Environ 2007;41(4):854-66.

[64] Keeler GJ, Dvonch T, Yip FY, Parker EA, Israel BA, Marsik FJ et al. Assessment of personal and community-level exposure to particulate matter among children with asthma in Detroit, Michigan, as part of Community Action Against Asthma (CAAA). Environ Health Persp 2002;110 (Suppl. 2):173-81. 
[65] Hänninen O, Hoek G, Mallone S, Chellini E, Katsouyanni K, Gariazzo C et al. Seasonal patterns of outdoor PM infiltration into indoor environments: review and meta-analysis of available studies from different climatological zones in Europe. Air Qual Atmos Health 2011;4:221-33.

[66] Nasir ZA, Colbeck I. Particulate pollution in different housing types in a UK suburban location, Sci Total Environ 2013;445-446:165-76. 
Table 1 - Main characteristics of the seven new single-family detached houses investigated in this study in terms of construction, equipment and occupancy

\begin{tabular}{|c|c|c|c|c|c|c|c|}
\hline & \multicolumn{7}{|c|}{ House code } \\
\hline & $\mathbf{A}$ & B & C & D & $\mathbf{E}$ & $\mathbf{F}$ & G \\
\hline Region & Centre & Pays-de-Loire & Ile-de-France & Ile-de-France & Pays-de-Loire & Rhône-Alpes & Rhône-Alpes \\
\hline Building type & $\begin{array}{l}\text { one storey single } \\
\text { detached house } \\
\text { with attached } \\
\text { garage }\end{array}$ & $\begin{array}{c}\text { two storey } \\
\text { single detached } \\
\text { house }\end{array}$ & $\begin{array}{l}\text { two storey } \\
\text { single } \\
\text { detached } \\
\text { house }\end{array}$ & $\begin{array}{l}\text { two storey } \\
\text { single } \\
\text { detached } \\
\text { house }\end{array}$ & $\begin{array}{c}\text { one storey } \\
\text { single detached } \\
\text { house }\end{array}$ & $\begin{array}{l}\text { two storey single } \\
\text { detached house }\end{array}$ & $\begin{array}{l}\text { two storey single } \\
\text { detached house }\end{array}$ \\
\hline Completion date & March 2008 & June 2009 & June 2009 & $\begin{array}{l}\text { December } \\
2009\end{array}$ & June 2009 & July 2009 & November 2009 \\
\hline Energy-Efficient building certification & $\begin{array}{l}\text { BBC-Effinergie } \\
\text { (obtained) }\end{array}$ & $\begin{array}{l}\text { BBC-Effinergie } \\
\text { (on going) }\end{array}$ & $\begin{array}{l}\text { Passivhaus } \\
\text { (obtained) }\end{array}$ & $\begin{array}{l}\text { Passivhaus } \\
\text { (obtained) }\end{array}$ & $\begin{array}{l}\text { in accordance } \\
\text { with Passivhaus }\end{array}$ & $\begin{array}{l}\text { in accordance with } \\
\text { Passivhaus and } \\
\text { with the } 14 \text { targets } \\
\text { defined by HQE } \\
\text { Programme }\end{array}$ & $\begin{array}{l}\text { in accordance with } \\
\text { Passivhaus and } \\
\text { with the } 14 \text { targets } \\
\text { defined by HQE } \\
\text { Programme }\end{array}$ \\
\hline $\begin{array}{l}\text { Building airtightness (vol/hour at } 50 \text { pascals pressure) } \\
{\left[\mathrm{m}^{3} / \mathrm{h} \cdot \mathrm{m}^{2} \text { at } 4 \text { pascals pressure }\right]}\end{array}$ & $\begin{array}{c}3.33 \\
{[0.41]}\end{array}$ & $\begin{array}{c}0.89 \\
{[0.19]}\end{array}$ & $\begin{array}{c}0.48 \\
{[0.12]}\end{array}$ & $\begin{array}{c}0.29 \\
{[0.06]}\end{array}$ & $\begin{array}{c}0.62 \\
{[0.11]}\end{array}$ & $\begin{array}{c}0.49^{\mathrm{a}} \\
{\left[0.15^{\mathrm{a}}\right]}\end{array}$ & $\begin{array}{c}0.49^{\mathrm{a}} \\
{\left[0.15^{\mathrm{a}}\right]}\end{array}$ \\
\hline $\begin{array}{l}\text { Annual consumption of conventional primary energy } \\
\qquad\left(\mathrm{kWh} / \mathrm{m}^{2} / \text { year }\right)\end{array}$ & 63 & 46 & missing data & missing data & 79 & missing data & missing data \\
\hline Construction type & masonry & timber & timber & timber & timber & timber & timber \\
\hline Insulation material & Fiberglass wool & $\begin{array}{c}\text { cellulose / } \\
\text { wood fiber / } \\
\text { wool wood }\end{array}$ & $\begin{array}{l}\text { cellulose / } \\
\text { wood fiber }\end{array}$ & $\begin{array}{l}\text { cellulose / } \\
\text { wood fiber }\end{array}$ & $\begin{array}{c}\text { cellulose / } \\
\text { wood fiber / } \\
\text { wool wood }\end{array}$ & Fiberglass wool & Fiberglass wool \\
\hline $\begin{array}{l}\text { Ventilation system } \\
\text { (number of normal fan speeds / one boost setting) }\end{array}$ & $\begin{array}{c}\operatorname{MVHR}^{\mathrm{c}} \\
(2 / 1)\end{array}$ & $\begin{array}{l}\text { MVHR }^{c} \\
\text { (3/none) }\end{array}$ & $\begin{array}{l}\text { MVHR }^{c} \\
\text { (4/none) }\end{array}$ & $\begin{array}{l}\text { MVHR }^{c} \\
\text { (4/none) }\end{array}$ & $\begin{array}{l}\text { MVHR }^{\mathrm{c}} \\
\text { (3/none) }\end{array}$ & $\begin{array}{c}\operatorname{MVHR}^{\mathrm{c}} \\
(1 / 1)\end{array}$ & $\begin{array}{c}\operatorname{MVHR}^{\mathrm{c}} \\
(1 / 1)\end{array}$ \\
\hline Main heating system & Heat pump & Wood stove & Heat pump & $\begin{array}{c}\text { Heat pump } \\
\text { (leisure wood } \\
\text { stove) }\end{array}$ & Wood stove & Heat pump & Heat pump \\
\hline Hot water production & $\begin{array}{l}\text { Thermodynamic } \\
\text { hot water }\end{array}$ & $\begin{array}{l}\text { Solar hot water } \\
\text { with electric } \\
\text { booster }\end{array}$ & $\begin{array}{l}\text { Solar hot } \\
\text { water with } \\
\text { electric } \\
\text { booster }\end{array}$ & $\begin{array}{l}\text { Solar hot } \\
\text { water with } \\
\text { electric } \\
\text { booster }\end{array}$ & $\begin{array}{l}\text { Electric hot } \\
\text { water tank }\end{array}$ & $\begin{array}{l}\text { Solar hot water } \\
\text { with electric } \\
\text { booster }\end{array}$ & $\begin{array}{l}\text { Solar hot water } \\
\text { with electric } \\
\text { booster }\end{array}$ \\
\hline Cooking fuel & electricity & electricity & electricity & electricity & electricity & electricity & electricity \\
\hline Choice of low-emissions building products and materials & no & yes & yes & yes & yes & yes & yes \\
\hline
\end{tabular}


Household composition

Occupation rate ${ }^{\mathrm{d}}$

Smoking status
2 adults / 1 children

0.75

No smoker
2 adults / 2 childrens

0.67

No smoker
2 adults / 2 childrens

0.67

No smoker
2 adults $/ 2$ childrens

0.67

No smoker
2 adults

0.40

No smoker
2 adults / 2 childrens

0.80

No smoker

${ }^{a}$ building air-tightness measured in a test house in the same housing scheme that buildings $\mathrm{F}$ and $\mathrm{G}$ and taken by default because of their similar construction method

${ }^{b}$ annual consumption of conventional primary energy for heating, cooling, ventilation, auxiliaries, production of domestic hot water and lighting facilities according to the French thermal regulation RT 2005 $\left(\mathrm{kWh} / \mathrm{m}^{2} /\right.$ year $)$

${ }^{c}$ mechanical ventilation with heat recovery

${ }^{\mathrm{d}}$ occupation rate $=$ number of inhabitant $/$ number of main rooms 
Table 2 - Strategy of sampling/measurement and accuracy/uncertainty of indoor air quality parameters

\begin{tabular}{|c|c|c|c|c|}
\hline Parameter & Sampling /Measurement methods & $\begin{array}{l}\text { Accuracy/ } \\
\text { uncertainty }\end{array}$ & $\begin{array}{c}\text { Sampling } \\
\text { /Measurement } \\
\text { locations }\end{array}$ & $\begin{array}{c}\text { Sampling } \\
\text { Measurement } \\
\text { durations }\end{array}$ \\
\hline TVOC & photoionisation detector & $\begin{array}{c} \pm 38 \mu \mathrm{g} / \mathrm{m} \\
\text { in.toluene eq. }\end{array}$ & living room & $\begin{array}{l}\text { Every } 10 \text { minutes } \\
\text { during each week of } \\
\text { investigation }\end{array}$ \\
\hline $\mathrm{CO}_{2}$ & non-dispersive infra-red probe & $\pm 50 \mathrm{ppm}$ & main bedroom & $\begin{array}{l}\text { Every } 10 \text { minutes } \\
\text { during each week of } \\
\text { investigation after the } \\
\text { inhabitants moved in }\end{array}$ \\
\hline VOC & $\begin{array}{l}\text { Sampling by passive sampler with Carbograph } 4 \\
\text { adsorbents / Analysis by, gas chromatography, } \\
\text { mass spectrometry and flame ionization }\end{array}$ & $\pm 15 \%$ & main bedroom & $\begin{array}{l}\text { During each week of } \\
\text { investigation }\end{array}$ \\
\hline aldehydes & $\begin{array}{c}\text { Sampling by passive sampler with } 2,4- \\
\text { dinitrophenylhydrazine (2,4-DNPH)-coated Florisil } \\
\text { / Analysis by high-performance liquid } \\
\text { chromatography and detection by UV absorption }\end{array}$ & $\pm 10 \%$ & main bedroom & $\begin{array}{l}\text { During each week of } \\
\text { investigation }\end{array}$ \\
\hline $\mathrm{CO}$ & electrochemical sensor & $\pm 3 \mathrm{ppm}$ & $\begin{array}{l}\text { Each room that } \\
\text { contained } \\
\text { combustion } \\
\text { equipment }\end{array}$ & $\begin{array}{l}\text { Every } 5 \text { minutes during } \\
\text { the winter week of } \\
\text { investigation }\end{array}$ \\
\hline $\mathrm{PM}_{2.5}$ & sampling system coupled to an air sampler & $\pm 13 \mu \mathrm{g} / \mathrm{m}^{3}$ & living room & $\begin{array}{l}\text { from } 5 \mathrm{pm} \text { to } 8 \text { am on } \\
\text { weekdays and for } 24 \\
\text { hours a day on } \\
\text { weekends during each } \\
\text { week of investigation }\end{array}$ \\
\hline Radon & Passive radon dosimeter & $\begin{array}{l} \pm 8 \text { to } 11 \\
\mathrm{~Bq} / \mathrm{m}^{3}\end{array}$ & $\begin{array}{l}\text { Living room } \\
\text { Main bedroom }\end{array}$ & $\begin{array}{l}\text { During more than two } \\
\text { months after the } \\
\text { inhabitants moved in }\end{array}$ \\
\hline
\end{tabular}


Table 3 - Measured ACH per room and estimation of average $\mathrm{ACH}\left(\mathrm{h}^{-1}\right)$ by house depending on the fan speed of the MVHR system in six houses (confidence interval). n.m.: not measured; n.e.: not estimated

\begin{tabular}{|c|c|c|c|c|}
\hline House code & $\begin{array}{c}\text { Fan speed of } \\
\text { MVHR system } \\
\end{array}$ & $\begin{array}{c}\text { Measured ACH of the } \\
\text { living room }\left(h^{-1}\right)\end{array}$ & $\begin{array}{c}\text { Measured ACH of the } \\
\text { main bedroom }\left(\mathrm{h}^{-1}\right)\end{array}$ & $\begin{array}{c}\text { Estimated average } \\
\text { ACH house }\left(h^{-1}\right)\end{array}$ \\
\hline A & $\begin{array}{l}\text { switched off } \\
\text { low } \\
\text { medium } \\
\text { boost }\end{array}$ & $\begin{array}{c}\text { n.m } \\
0,4(0,3-0,6) \\
0,8(0,6-0,9) \\
\text { n.m }\end{array}$ & $\begin{array}{c}\text { n.m } \\
0,5(0,3-0,6) \\
0,7(0,6-0,8) \\
\text { n.m }\end{array}$ & $\begin{array}{c}\text { n.e } \\
0,6(0,4-0,7) \\
0,9(0,8-1,1) \\
\text { n.e }\end{array}$ \\
\hline B & $\begin{array}{l}\text { switched off } \\
\text { low } \\
\text { medium } \\
\text { high }\end{array}$ & $\begin{array}{c}0,05(0,04-0,06) \\
0,2(0,1-0,3) \\
0,3(0,2-0,4) \\
0,6^{\mathrm{b}}\end{array}$ & $\begin{array}{c}0,04(0,03-0,05) \\
0,6(0,5-0,7) \\
1,2(1,1-1,4) \\
1,2^{\mathrm{b}}\end{array}$ & $\begin{array}{c}0,04(0,03-0,05) \\
0,3(0,2-0,4) \\
0,5(0,4-0,6) \\
\text { n.e }\end{array}$ \\
\hline $\mathrm{C}$ & $\begin{array}{l}\text { switched off } \\
\text { low } \\
\text { medium } \\
\text { high } \\
\text { very high }\end{array}$ & $\begin{array}{c}\quad<<0,01^{\mathrm{c}} \\
0,3(0,2-0,4) \\
0,7(0,6-0,7) \\
0,6(0,5-0,7) \\
1,3(1,2-1,4)\end{array}$ & $\begin{array}{c}<<0,01^{\mathrm{c}} \\
0,1(0,03-0,2) \\
0,5(0,4-0,5) \\
0,5(0,4-0,6) \\
0,8(0,7-0,9)\end{array}$ & $\begin{array}{c}<<0,01 \\
0,3(0,1-0,4) \\
0,5(0,4-0,6) \\
0,5(0,4-0,6) \\
1(0,8-1,1)\end{array}$ \\
\hline $\mathrm{D}$ & $\begin{array}{l}\text { switched off } \\
\text { low } \\
\text { medium } \\
\text { high } \\
\text { very high }\end{array}$ & $\begin{array}{c}0,1^{\mathrm{b}} \\
0,2(0,1-0,3) \\
0,3(0,2-0,4) \\
0,4^{\mathrm{b}} \\
\text { n.m }\end{array}$ & $\begin{array}{c}<<0,01^{\mathrm{c}} \\
0,3(0,3-0,4) \\
0,4(0,3-0,5) \\
0,7(0,6-0,8) \\
\quad \text { n.m }\end{array}$ & $\begin{array}{c}<<0,01 \\
0,2(0,1-0,2) \\
0,3(0,2-0,3) \\
0,4 \\
\text { n.e }\end{array}$ \\
\hline E & $\begin{array}{l}\text { switched off } \\
\text { low } \\
\text { medium } \\
\text { high }\end{array}$ & $\begin{array}{c}0,02^{\mathrm{b}} \\
0,2^{\mathrm{b}} \\
0,6(0,5-0,7) \\
0,3^{\mathrm{b}}\end{array}$ & $\begin{array}{c}0,1^{\mathrm{b}} \\
0,2^{\mathrm{b}} \\
0,4(0,2-0,5) \\
0,3^{\mathrm{b}}\end{array}$ & $\begin{array}{c}0,02 \\
0,1 \\
0,4(0,3-0,4) \\
0,24\end{array}$ \\
\hline $\mathrm{F}$ & $\begin{array}{l}\text { switched off } \\
\text { normal } \\
\text { boost }\end{array}$ & $\begin{array}{c}0,2^{\mathrm{b}} \\
0,6(0,5-0,6) \\
\text { n.m }\end{array}$ & $\begin{array}{c}0,1^{\mathrm{b}} \\
0,5(0,5-0,6) \\
\text { n.m }\end{array}$ & $\begin{array}{c}0,1 \\
0,5(0,4-0,5) \\
\text { n.e }\end{array}$ \\
\hline
\end{tabular}

${ }^{6}$ graphically estimated ACH value from the decay curves of the tracer gas concentration because of the loss of data / confidence interval not calculated

${ }^{\mathrm{c}}$ : ACH value near zero but not quantifiable because of the lack of decrease of tracer gas concentration 
Table 4 - Descriptive statistics of $\mathrm{CO}_{2}$ level (ppm), $\mathrm{T}\left({ }^{\circ} \mathrm{C}\right)$ and $\mathrm{RH}(\%)$ measured weekly in the main bedrooms of six occupied houses by season. (Sum: summer; Win: winter; P25: $25^{\text {th }}$ percentile; P75: $75^{\text {th }}$ percentile; n.a.: not available)

\begin{tabular}{|c|c|c|c|c|c|c|c|c|c|c|c|c|c|}
\hline \multirow{2}{*}{$\begin{array}{c}\text { House } \\
\text { code }\end{array}$} & & \multicolumn{4}{|c|}{$\mathrm{CO}_{2}(\mathrm{ppm})$} & \multicolumn{4}{|c|}{$\mathrm{T}\left({ }^{\circ} \mathrm{C}\right)$} & \multicolumn{4}{|c|}{ RH (\%) } \\
\hline & & Mean [min-max] & $\mathbf{P} 25$ & Median & P75 & Mean [min-max] & P25 & Median & P75 & Mean [min-max] & $\mathbf{P 2 5}$ & Median & P75 \\
\hline \multirow{2}{*}{ A } & Sum & $695[372-1840]$ & 463 & 578 & 911 & $25.2[23.2-27.1]$ & 24.6 & 25.1 & 25.7 & $47.4[39.2-57.9]$ & 45.1 & 47.4 & 49.8 \\
\hline & Win & 788 [378-1207] & 684 & 811 & 883 & $20.5[14.2-22.6]$ & 20.0 & 20.5 & 21.0 & $30.8[21.3-41.2]$ & 28.4 & 30.0 & 33.0 \\
\hline \multirow{2}{*}{ B } & Sum & 381 [291-861] & 314 & 351 & 413 & $24.2[19.8-28.0]$ & 23.1 & 24.2 & 25.4 & $46.3[26.0-64.9]$ & 42.7 & 46.2 & 51.4 \\
\hline & Win & 722 [467-1257] & 595 & 701 & 823 & n.a. & n.a. & n.a. & n.a. & n.a. & n.a. & n.a. & n.a. \\
\hline \multirow{2}{*}{$\mathrm{C}$} & Sum & 879 [366-1942] & 501 & 656 & 1371 & $20.6[19.3-25.0]$ & 19.8 & 20.3 & 21.1 & $44.9[33.2-53.4]$ & 42.6 & 45.1 & 47.0 \\
\hline & Win & 920 [415-1679] & 586 & 778 & 1320 & $19.7[16.8-26.7]$ & 19.2 & 19.5 & 19.8 & $34.7[24.1-41.2]$ & 32.7 & 34.3 & 37.0 \\
\hline \multirow{2}{*}{$\mathrm{D}$} & Sum & 738 [331-1829] & 367 & 449 & 1293 & $21.9[18.7-25.1]$ & 21.2 & 21.6 & 22.7 & $47.9[38.2-59.4]$ & 45.7 & 48.3 & 50.2 \\
\hline & Win & $1013[430-2030]$ & 484 & 768 & 1654 & n.a. & n.a. & n.a. & n.a. & n.a. & n.a. & n.a. & n.a. \\
\hline \multirow{2}{*}{ E } & Sum & 451 [361-1229] & 379 & 406 & 471 & $21.6[17.9-23.2]$ & 21.1 & 22.0 & 22.4 & $58.1[34.4-75.9]$ & 52.7 & 58.1 & 64.5 \\
\hline & Win & $622[360-1263]$ & 475 & 573 & 701 & n.a. & n.a. & n.a. & n.a. & n.a. & n.a. & n.a. & n.a. \\
\hline \multirow{2}{*}{$\mathrm{F}$} & Sum & 504 [355-1032] & 409 & 460 & 527 & $25.7[24.6-27.2]$ & 25.3 & 25.7 & 26.0 & $46.9[36.6-62.1]$ & 43.8 & 45.9 & 48.9 \\
\hline & Win & $633[415-1115]$ & 521 & 642 & 705 & 21.8 [19.1-33.6] & 21.1 & 21.6 & 22.2 & $30.5[14.4-45.3]$ & 27.9 & 29.3 & 33.2 \\
\hline
\end{tabular}


Table 5 - Indoor TVOC, VOC and aldehyde levels $\left(\mu \mathrm{g} / \mathrm{m}^{3}\right)$ measured weekly in seven new low-energy houses at the pre-occupancy stage (Pre) and during occupancy (Sum: summer; Win: winter). LI: Limit of identification $\left(<1 \mu \mathrm{g} / \mathrm{m}^{3}\right)$; LD: limit of detection; LQ: limit of quantification; n.a.: not available; n.m.: not measured; Q.F.: quantification frequency

\begin{tabular}{|c|c|c|c|c|c|c|c|c|c|c|c|c|c|c|c|c|c|c|c|}
\hline \multirow[t]{2}{*}{ Chemical class and Compounds } & \multirow{2}{*}{$\begin{array}{l}\text { Q.F } \\
(\%)\end{array}$} & \multicolumn{3}{|c|}{$\begin{array}{c}\text { House } \\
\text { A }\end{array}$} & \multicolumn{3}{|c|}{$\begin{array}{c}\text { House } \\
\text { B } \\
\end{array}$} & \multicolumn{3}{|c|}{$\begin{array}{c}\text { House } \\
\text { C }\end{array}$} & \multicolumn{3}{|c|}{$\begin{array}{c}\text { House } \\
\text { D } \\
\end{array}$} & \multicolumn{3}{|c|}{$\begin{array}{c}\text { House } \\
\text { E }\end{array}$} & \multirow{2}{*}{$\begin{array}{c}\begin{array}{c}\text { House } \\
\text { G }\end{array} \\
\text { Pre } \\
\end{array}$} & \multicolumn{2}{|c|}{$\begin{array}{c}\text { House } \\
F \\
\end{array}$} \\
\hline & & Pre & Sum & Win & Pre & Sum & Win & Pre & Sum & Win & Pre & Sum & Win & Pre & Sum & Win & & Sum & Win \\
\hline$T_{V O C}{ }^{\mathrm{a}}$ & & 130 & 169 & $<\mathrm{LD}$ & 15 & 6 & 128 & 1042 & 276 & $<\mathrm{LD}$ & 525 & 92 & n.a & 3087 & 17 & 569 & n.m & 12 & 96 \\
\hline \multicolumn{20}{|l|}{ Aromatic hydrocarbons } \\
\hline alkylbenzenes ${ }^{\mathrm{b}}$ & 72 & $<\mathrm{LI}$ & $<\mathrm{LI}$ & 25.1 & 19 & $<\mathrm{LI}$ & 9.8 & 25.9 & 14.7 & 29 & 5.8 & 30 & 26 & 92.1 & $<$ LI & 28 & $<\mathrm{LI}$ & 20 & 33 \\
\hline 2-methyl-decahydronaphthalene ${ }^{b}$ & 6 & $<\mathrm{LI}$ & $<\mathrm{LI}$ & $<$ LI & $<\mathrm{LI}$ & $<\mathrm{LI}$ & $<\mathrm{LI}$ & 4.6 & $<\mathrm{LI}$ & $<\mathrm{LI}$ & $<\mathrm{LI}$ & $<\mathrm{LI}$ & $<\mathrm{LI}$ & $<\mathrm{LI}$ & $<\mathrm{LI}$ & $<\mathrm{LI}$ & $<\mathrm{LI}$ & $<\mathrm{LI}$ & $<\mathrm{LI}$ \\
\hline 1,2,4-trimethylbenzene ${ }^{c}$ & 100 & 7.4 & 4.7 & 5.2 & 5.4 & 4.7 & 4.7 & 17.8 & 7.3 & 2.9 & 12 & 17 & 12 & 1.4 & 7.8 & 7.9 & 160 & 4.3 & 5.6 \\
\hline benzene $^{c}$ & 78 & 0.8 & 1.3 & 5 & 1 & 1.2 & 1.8 & $<\mathrm{LQ}$ & 1 & 1.7 & 1.9 & $<\mathrm{LD}$ & 1.2 & 1 & $<\mathrm{LQ}$ & 1.8 & 1.1 & $<\mathrm{LQ}$ & 5.8 \\
\hline ethylbenzene $^{\mathrm{c}}$ & 94 & $<\mathrm{LQ}$ & 1.9 & 1.8 & 3.6 & 1.7 & 13.2 & 5.2 & 1.3 & 1.3 & 3.1 & 1.9 & 2.2 & 222.4 & 5.1 & 6.8 & 83.2 & 1.5 & 4.5 \\
\hline styrene $^{c}$ & 83 & $<\mathrm{LQ}$ & $<\mathrm{LD}$ & 1.9 & 5 & 1.8 & 4 & $<\mathrm{LD}$ & 1.3 & 1.2 & 1.4 & 1.8 & 1.6 & 7.2 & 0.2 & 0.8 & 4.4 & 1.8 & 5.4 \\
\hline toluene ${ }^{c}$ & 94 & 2 & 15.6 & 20 & 11 & 5.4 & 6.2 & 19.6 & 5.1 & 4.2 & 5.6 & $<\mathrm{LQ}$ & 17 & 36.7 & 5.1 & 5.3 & 552 & 6.5 & 17 \\
\hline $\mathrm{m}+\mathrm{p}$-xylene $\mathrm{c}^{\mathrm{c}}$ & 89 & $<\mathrm{LQ}$ & 5 & 5 & 10.7 & 3.7 & 38.4 & 15.3 & 2.9 & 2 & 11 & 4.7 & 6.2 & 569.3 & $<\mathrm{LQ}$ & 22 & 734 & 3 & 12 \\
\hline o-xylene ${ }^{c}$ & 100 & 4.9 & 3.8 & 3.8 & 5.4 & 2 & 13.4 & 5.8 & 3.1 & 1.9 & 5.4 & 3.8 & 3.8 & 163.6 & 5.4 & 8.4 & 356 & 2.5 & 2.6 \\
\hline \multicolumn{20}{|l|}{ Aliphalic hydrocarbons } \\
\hline pentane (sum of isomeres) ${ }^{b}$ & 56 & $<$ LI & $<\mathrm{LI}$ & 13.8 & 5.6 & $<\mathrm{LI}$ & $<\mathrm{LI}$ & $<\mathrm{LI}$ & 15.4 & 5.4 & 7.8 & 10 & 5.5 & $<\mathrm{LI}$ & $<\mathrm{LI}$ & 3.7 & $<\mathrm{LI}$ & 3.3 & 93 \\
\hline hexane ${ }^{b}$ & 11 & $<\mathrm{LI}$ & 3.7 & $<\mathrm{LI}$ & $<\mathrm{LI}$ & $<\mathrm{LI}$ & $<\mathrm{LI}$ & $<\mathrm{LI}$ & $<\mathrm{LI}$ & $<\mathrm{LI}$ & $<\mathrm{LI}$ & $<\mathrm{LI}$ & 2.4 & $<\mathrm{LI}$ & $<\mathrm{LI}$ & $<\mathrm{LI}$ & $<\mathrm{LI}$ & $<\mathrm{LI}$ & $<\mathrm{LI}$ \\
\hline octane $^{b}$ & 6 & $<\mathrm{LI}$ & $<\mathrm{LI}$ & $<\mathrm{LI}$ & $<\mathrm{LI}$ & $<\mathrm{LI}$ & $<\mathrm{LI}$ & $<\mathrm{LI}$ & $<\mathrm{LI}$ & $<\mathrm{LI}$ & $<\mathrm{LI}$ & $<$ LI & $<\mathrm{LI}$ & 11.5 & $<\mathrm{LI}$ & $<\mathrm{LI}$ & $<\mathrm{LI}$ & $<\mathrm{LI}$ & $<\mathrm{LI}$ \\
\hline nonane (sum of isomeres) ${ }^{b}$ & 17 & $<\mathrm{LI}$ & 6.9 & $<\mathrm{LI}$ & $<\mathrm{LI}$ & $<\mathrm{LI}$ & $<\mathrm{LI}$ & $<\mathrm{LI}$ & $<\mathrm{LI}$ & $<\mathrm{LI}$ & $<\mathrm{LI}$ & $<$ LI & 12 & 49.2 & $<\mathrm{LI}$ & $<\mathrm{LI}$ & $<\mathrm{LI}$ & $<\mathrm{LI}$ & $<\mathrm{LI}$ \\
\hline nonane $^{\mathrm{b}}$ & 22 & $<\mathrm{LI}$ & 2.2 & $<\mathrm{LI}$ & $<\mathrm{LI}$ & $<\mathrm{LI}$ & $<\mathrm{LI}$ & 30.1 & $<\mathrm{LI}$ & $<\mathrm{LI}$ & 12 & $<$ LI & $<\mathrm{LI}$ & 16.7 & $<\mathrm{LI}$ & $<\mathrm{LI}$ & $<\mathrm{LI}$ & $<\mathrm{LI}$ & $<\mathrm{LI}$ \\
\hline decane (sum of isomeres) ${ }^{b}$ & 28 & $<\mathrm{LI}$ & 18.7 & $<\mathrm{LI}$ & $<\mathrm{LI}$ & $<\mathrm{LI}$ & $<\mathrm{LI}$ & 61.2 & $<\mathrm{LI}$ & $<\mathrm{LI}$ & 45 & $<\mathrm{LI}$ & 43 & 52.9 & $<\mathrm{LI}$ & $<\mathrm{LI}$ & $<\mathrm{LI}$ & $<\mathrm{LI}$ & $<\mathrm{LI}$ \\
\hline n-décane ${ }^{c}$ & 100 & 2.2 & 7.5 & 4.6 & 24.1 & 16 & 3.4 & 192.1 & 5.1 & 2.1 & 57 & 41 & 68 & 101.8 & 14 & 6.5 & 247 & 2 & 6.8 \\
\hline undecane (sum of isomeres) ${ }^{b}$ & 28 & $<\mathrm{LI}$ & 9.4 & $<\mathrm{LI}$ & $<\mathrm{LI}$ & $<\mathrm{LI}$ & $<\mathrm{LI}$ & 88.6 & $<\mathrm{LI}$ & $<\mathrm{LI}$ & 23 & $<\mathrm{LI}$ & 39 & 46.2 & $<\mathrm{LI}$ & $<\mathrm{LI}$ & $<\mathrm{LI}$ & $<\mathrm{LI}$ & $<\mathrm{LI}$ \\
\hline n-undécane ${ }^{c}$ & 100 & 7.2 & 8.4 & 16.5 & 37.9 & 24 & 3.4 & 127.7 & 12.6 & 2.7 & 27 & 28 & 39 & 93.4 & 26 & 5.7 & 313 & 3.1 & 22 \\
\hline dodecane (sum of isomeres) ${ }^{b}$ & 6 & $<\mathrm{LI}$ & $<\mathrm{LI}$ & $<$ LI & $<\mathrm{LI}$ & $<\mathrm{LI}$ & $<\mathrm{LI}$ & $<\mathrm{LI}$ & $<\mathrm{LI}$ & $<\mathrm{LI}$ & $<\mathrm{LI}$ & $<$ LI & $<\mathrm{LI}$ & 15.6 & $<\mathrm{LI}$ & $<\mathrm{LI}$ & $<\mathrm{LI}$ & $<\mathrm{LI}$ & $<\mathrm{LI}$ \\
\hline alkene $^{b}$ & 11 & $<\mathrm{LI}$ & $<\mathrm{LI}$ & $<\mathrm{LI}$ & $<\mathrm{LI}$ & $<\mathrm{LI}$ & $<\mathrm{LI}$ & $<\mathrm{LI}$ & $<\mathrm{LI}$ & $<\mathrm{LI}$ & $<\mathrm{LI}$ & $<\mathrm{LI}$ & $<\mathrm{LI}$ & 16.2 & $<\mathrm{LI}$ & $<\mathrm{LI}$ & $<\mathrm{LI}$ & 3.4 & $<\mathrm{LI}$ \\
\hline alkylcyclopentane $^{\mathrm{b}}$ & 6 & $<\mathrm{LI}$ & $<\mathrm{LI}$ & $<\mathrm{LI}$ & $<\mathrm{LI}$ & $<\mathrm{LI}$ & $<\mathrm{LI}$ & 9.7 & $<\mathrm{LI}$ & $<\mathrm{LI}$ & $<\mathrm{LI}$ & $<\mathrm{LI}$ & $<\mathrm{LI}$ & $<\mathrm{LI}$ & $<\mathrm{LI}$ & $<\mathrm{LI}$ & $<\mathrm{LI}$ & $<\mathrm{LI}$ & $<\mathrm{LI}$ \\
\hline alkylcyclohexanes $^{\mathrm{b}}$ & 22 & $<\mathrm{LI}$ & 5.7 & $<\mathrm{LI}$ & $<\mathrm{LI}$ & $<\mathrm{LI}$ & $<\mathrm{LI}$ & 196.1 & $<\mathrm{LI}$ & $<\mathrm{LI}$ & $<\mathrm{LI}$ & $<$ LI & 16 & 107 & $<\mathrm{LI}$ & $<\mathrm{LI}$ & $<\mathrm{LI}$ & $<\mathrm{LI}$ & $<\mathrm{LI}$ \\
\hline cyclohexane $^{b}$ & 17 & 4.6 & $<\mathrm{LI}$ & $<\mathrm{LI}$ & 2.5 & $<\mathrm{LI}$ & $<\mathrm{LI}$ & $<\mathrm{LI}$ & $<\mathrm{LI}$ & $<\mathrm{LI}$ & $<\mathrm{LI}$ & $<\mathrm{LI}$ & $<\mathrm{LI}$ & 16.8 & $<\mathrm{LI}$ & $<\mathrm{LI}$ & $<\mathrm{LI}$ & $<\mathrm{LI}$ & $<\mathrm{LI}$ \\
\hline methylcyclohexane $^{b}$ & 6 & $<\mathrm{LI}$ & $<\mathrm{LI}$ & $<\mathrm{LI}$ & 5.6 & $<\mathrm{LI}$ & $<\mathrm{LI}$ & $<\mathrm{LI}$ & $<\mathrm{LI}$ & $<\mathrm{LI}$ & $<\mathrm{LI}$ & $<\mathrm{LI}$ & $<\mathrm{LI}$ & $<\mathrm{LI}$ & $<\mathrm{LI}$ & $<\mathrm{LI}$ & $<\mathrm{LI}$ & $<\mathrm{LI}$ & $<\mathrm{LI}$ \\
\hline \multicolumn{20}{|l|}{ Alcohol } \\
\hline phénol $^{\text {b }}$ & 28 & $<\mathrm{LI}$ & 4.7 & 15.1 & 4.9 & $<\mathrm{LI}$ & $<\mathrm{LI}$ & $<\mathrm{LI}$ & $<\mathrm{LI}$ & $<\mathrm{LI}$ & $<\mathrm{LI}$ & $<\mathrm{LI}$ & 10 & $<\mathrm{LI}$ & $<\mathrm{LI}$ & $<\mathrm{LI}$ & $<\mathrm{LI}$ & 2.7 & $<\mathrm{LI}$ \\
\hline
\end{tabular}


Aldehydes

\begin{tabular}{|c|c|c|c|c|c|c|c|c|c|c|c|c|c|c|c|c|c|c|}
\hline \multirow{3}{*}{$\begin{array}{l}\text { benz } \\
\text { sovale }\end{array}$} & 39 & $<\mathrm{LI}$ & 7 & $<$ LI & 3.6 & $<\mathrm{LI}$ & 5.4 & $<$ LI & $<$ LI & $<\mathrm{LI}$ & $<$ LI & $<$ LI & $<\mathrm{LI}$ & 23.6 & $<\mathrm{LI}$ & 2 & 24.9 & 3.7 \\
\hline & 67 & 5.7 & 3.2 & $<\mathrm{LI}$ & 6 & $<\mathrm{LI}$ & $<\mathrm{LI}$ & 4.4 & 7.5 & 4 & $<\mathrm{LI}$ & 8.7 & 4.5 & 13.1 & 7.3 & 5 & $<\mathrm{LI}$ & 3.9 \\
\hline & 28 & 5.3 & 5.8 & $<\mathrm{LI}$ & 4 & $<\mathrm{LI}$ & $<\mathrm{LI}$ & $<\mathrm{LI}$ & 4.8 & $<\mathrm{LI}$ & $<\mathrm{LI}$ & $<\mathrm{LI}$ & $<\mathrm{LI}$ & $<\mathrm{LI}$ & $<\mathrm{LI}$ & $<\mathrm{LI}$ & $<\mathrm{LI}$ & 3.7 \\
\hline acetaldehyde $^{c}$ & 100 & 5 & 6.6 & 5.8 & 16.1 & 7.9 & 22.1 & 6.9 & 22.9 & 18.2 & 26 & 16 & 26 & 30.8 & 23 & 29 & 59.3 & 7.8 \\
\hline formaldehyde ${ }^{c}$ & 100 & 12 & 28.5 & 12.3 & 48.3 & 20 & 31.1 & 61.3 & 41.4 & 39.7 & 6.1 & 13 & 12 & 21.7 & 17 & 20 & 31.6 & 21 \\
\hline hexaldehyde $^{c}$ & 100 & 83.7 & 44.9 & 14.6 & 112 & 29 & 36.1 & 170.1 & 105 & 48.8 & 70 & 78 & 93 & 684.9 & 96 & 88 & 856 & 58 \\
\hline acrolein $^{c}$ & 94 & 0.6 & 0.9 & $<\mathrm{LD}$ & 2.8 & 0.9 & 2.4 & 2.1 & 4.1 & 1.7 & 1.6 & 1.5 & 1.3 & 3.1 & 1.6 & 2.9 & 4.8 & 1 \\
\hline
\end{tabular}

Ketones

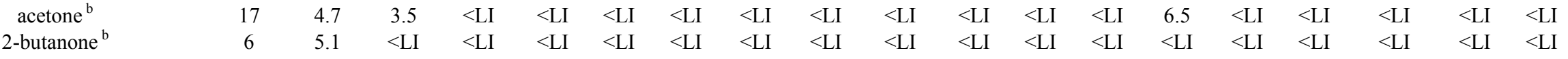

Esters

dibutyl decanedioate ${ }^{\mathrm{b}}$

ethylacetate $^{b}$

n-butylacetate ${ }^{b}$

$\begin{array}{ccccccc}6 & <\text { LI } & <\text { LI } & <\text { LI } & <\text { LI } & <\text { LI } & <\text { LI } \\ 22 & 5.3 & <\text { LI } & 6.6 & <\text { LI } & <\text { LI } & 2.4\end{array}$

Glycol/glycoether

1,2-propanediol ${ }^{\mathrm{b}}$

$<$ LI $<$ LI

2-butoxy ethanol /EGBE ${ }^{\mathrm{c}}$

28

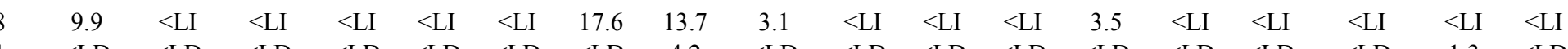

Terpenes

$\begin{array}{ccccccccccccccccccccc}\text { alpha-pinene }^{\text {b }} & 100 & 19 & 16.4 & 13.7 & 43.2 & 13 & 9 & 56.4 & 25 & 13.6 & 10 & 6.4 & 6.6 & 294.4 & 18 & 6.8 & 47.4 & 5.8 & 13 \\ \text { beta-pinene }^{\text {b }} & 39 & 5 & 3.9 & <\text { LI } & 6.8 & <\text { LI } & <\text { LI } & 35.4 & 5.8 & 2.3 & <\text { LI } & <\text { LI } & <\text { LI } & \text { n.a } & <\text { LI } & <\text { LI } & <\text { LI } & <\text { LI } & <\text { LI } \\ \text { camphene }^{\text {b }} & 72 & 2.9 & <\text { LI } & <\text { LI } & 8.2 & <\text { LI } & 2.6 & 5.8 & 4.9 & 5.3 & <\text { LI } & 3.4 & 4.2 & 23.7 & <\text { LD } & 3.2 & 10.1 & 4.5 & 7.9 \\ \text { eucalyptol }^{\text {b }} & 6 & <\text { LI } & <\text { LI } & <\text { LI } & <\text { LI } & <\text { LI } & <\text { LI } & <\text { LI } & <\text { LI } & 2.6 & <\text { LI } & <\text { LI } & <\text { LI } & <\text { LI } & <\text { LI } & <\text { LI } & <\text { LI } & <\text { LI } & <\text { LI } \\ \text { limonene }^{\text {b }} & 89 & 5.5 & 6.3 & 9.2 & 18.3 & 6.6 & 4.7 & 24.5 & 13.5 & 9.4 & 9.2 & <\text { LI } & 7.1 & 92.3 & 11 & 9.2 & <\text { LI } & 2.9 & 11 \\ \text { 3-carene }^{\text {b }} & 33 & <\text { LI } & <\text { LI } & <\text { LI } & 6.6 & <\text { LI } & <\text { LI } & 22.5 & 8.1 & 4.5 & <\text { LI } & 2.3 & <\text { LI } & 48.6 & <\text { LI } & <\text { LI } & <\text { LI } & <\text { LI } & <\text { LI } \\ \text { 4-carene }^{\text {b }} & 6 & <\text { LI } & <\text { LI } & <\text { LI } & <\text { LI } & <\text { LI } & <\text { LI } & <\text { LI } & <\text { LI } & <\text { LI } & <\text { LI } & <\text { LI } & <\text { LI } & 6.5 & <\text { LI } & <\text { LI } & <\text { LI } & <\text { LI } & <\text { LI }\end{array}$

Chlorinated organic compounds chloroalkane ${ }^{\mathrm{b}}$

tetrachloroethylene ${ }^{\mathrm{c}}$

trichloroethylene ${ }^{\mathrm{c}}$

1,4-dichlorobenzene ${ }^{\mathrm{c}}$

Acide

acetic acid $^{\mathrm{b}}$

$39<\mathrm{LI}<\mathrm{LI}$

$<$ LI 
${ }^{\mathrm{b}}$ calibrated as toluene equivalent

${ }^{\mathrm{c}}$ calibrated with a specific calibration 
Table 6 - Comparison of the measured air exhaust rate $(1 / \mathrm{s})$ for four houses to the French regulations concerning residential-building ventilation [14].

\begin{tabular}{|c|c|c|c|c|c|}
\hline House code & Rooms & $\begin{array}{l}\text { Measured air exhaust rate } \\
\text { (1/s) for high (boost for } \\
\text { houses A and F) fan speed of } \\
\text { MVHR system } \\
\end{array}$ & $\begin{array}{l}\text { Achievable air } \\
\text { exhaust rate (1/s) }\end{array}$ & $\begin{array}{l}\text { Measured air exhaust rate } \\
\text { (1/s) in kitchen for low } \\
\text { (normal for house F) fan } \\
\text { speed of MVHR system } \\
\end{array}$ & $\begin{array}{c}\text { Minimum values } \\
\text { of reduced air } \\
\text { exhaust rate (1/s) } \\
\text { in kitchen }\end{array}$ \\
\hline A & Bathroom 1 & $9 \pm 3.6$ & 8 & - & - \\
\hline B & Bathroom 1 & $7 \pm 3.6$ & 8 & - & - \\
\hline \multirow{4}{*}{$\mathrm{C}$} & $\mathrm{WC1}$ & $10 \pm 3.6$ & 8 & - & - \\
\hline & Bathroom 1 & $12 \pm 3.6$ & 8 & - & - \\
\hline & Bathroom 2 & $11 \pm 3.6$ & 8 & - & - \\
\hline & $\begin{array}{l}\text { Living room conbined } \\
\text { with the kitchen }\end{array}$ & $12 \pm 3.6$ & 38 & $8 \pm 3.6$ & 13 \\
\hline
\end{tabular}


Table 7 - Comparison of geometric concentrations of TVOC and of the most frequently quantified VOC and aldehydes in this study in three unoccupied houses (A, B and D) to the results of previous studies conducted in unoccupied and ventilated dwellings less than one year old. Some of these houses may have been energy-efficient and/or built with low-emitting material. n.m.: not measured

\begin{tabular}{|c|c|c|c|c|c|c|c|c|c|c|}
\hline Number and type of buildings & $\begin{array}{c}\text { Our study } \\
3 \mathrm{SDH}^{\mathrm{a}}\end{array}$ & $\begin{array}{c}{[\mathbf{1 0}]} \\
2 \mathrm{APA}^{\mathrm{b}}\end{array}$ & $\begin{array}{c}{[26]} \\
4 \mathrm{SDH}^{\mathrm{a}}\end{array}$ & $\begin{array}{c}{[29]} \\
1 \mathrm{SDH}^{\mathrm{a}}\end{array}$ & $\frac{[\mathbf{3 0}]}{12 \mathrm{APA}^{\mathrm{b}}}$ & $\begin{array}{c}{[27]} \\
1 \mathrm{SDH}^{\mathrm{a}}\end{array}$ & $\begin{array}{c}{[28]} \\
11 \mathrm{SDH}^{\mathrm{a}}\end{array}$ & $\frac{\text { [31] }}{14 \mathrm{APA}^{\mathrm{b}}}$ & $\begin{array}{c}\text { [32] } \\
228 \mathrm{APA}^{\mathrm{b}}\end{array}$ & $\begin{array}{c}{[33]} \\
\mathrm{APA}^{\mathrm{b}}\end{array}$ \\
\hline Characteristic of buildings & $\begin{array}{c}\mathrm{EE}^{\mathrm{c}} \\
\mathrm{LE}^{\mathrm{d}} \text { for two }\end{array}$ & $\mathrm{EE}^{\mathrm{c}}$ and $\mathrm{LE}^{\mathrm{d}}$ & $\mathrm{EE}^{\mathrm{c}}$ & $L E^{\mathrm{d}}$ & $\mathrm{LE}^{\mathrm{d}}$ & - & - & - & - & - \\
\hline TVOCe & $100,8^{\mathrm{eg}}$ & $254^{\mathrm{f}}-31^{\mathrm{f}}$ & $1429^{\text {fth }}-1954^{\text {fh }}$ & $5000^{\mathrm{f}}$ & $250^{\mathrm{fi}}-911^{\mathrm{fi}}$ & n.m. & $1520^{\mathrm{fg}}-2720^{\mathrm{fg}}$ & $780^{\text {fl }}$ & $645^{\text {th }}-1606^{\text {th }}$ & $517^{\mathrm{f}}$ \\
\hline hexaldehyde & $86,7^{\mathrm{g}}$ & 0 & n.m. & 33 & $44^{i}-83^{i}$ & 267 & $65,8^{\mathrm{g}}-107,6^{\mathrm{g}}$ & $21^{\mathrm{h}}$ & n.m. & n.m. \\
\hline alpha-pinene & $20,2^{\mathrm{g}}$ & 1 & n.m. & 50 & $46^{\mathrm{i}}-89^{\mathrm{i}}$ & 232 & $90,7^{\mathrm{g}}-156,3^{\mathrm{g}}$ & $61^{\mathrm{h}}$ & $1,0^{\mathrm{h}}-7,1^{\mathrm{h}}$ & n.m. \\
\hline n-undecane & $19,6^{\mathrm{g}}$ & n.m. & $57^{\mathrm{h}}-75^{\mathrm{h}}$ & 13 & $50^{\mathrm{i}}$ & n.m. & $7^{g}-23^{g}$ & $18^{\mathrm{h}}$ & $1,6^{\mathrm{h}}-4,3^{\mathrm{h}}$ & n.m. \\
\hline ormaldehyde & $15,2^{\mathrm{g}}$ & $16-21$ & $41^{\mathrm{h}}-59^{\mathrm{h}}$ & 120 & $8^{i}-10^{i}$ & 94,9 & $41,7^{\mathrm{g}}-44,2^{\mathrm{g}}$ & $19^{\mathrm{h}}$ & $40,1^{\mathrm{h}}-65,9^{\mathrm{h}}$ & 457 \\
\hline n-decane & $14,5^{\mathrm{g}}$ & n.m. & n.m. & 17 & $34^{\mathrm{i}}$ & n.m. & $12,2^{g}-31,9^{g}$ & $32^{\mathrm{h}}$ & $3,3^{\mathrm{h}}-5,2^{\mathrm{h}}$ & n.m. \\
\hline acetaldehyde & $12,9^{\mathrm{g}}$ & $4-8$ & n.m. & n.m. & $6^{i}-7^{i}$ & 42,5 & $18^{g}-36^{g}$ & n.m. & $7,2^{\mathrm{h}}-12,2^{\mathrm{h}}$ & n.m. \\
\hline limonene & $9,7^{\mathrm{g}}$ & n.m. & n.m. & 4,8 & $140^{\mathrm{i}}$ & 40,3 & $16,1^{\mathrm{g}}-30^{\mathrm{g}}$ & $12^{\mathrm{h}}$ & n.m. & n.m. \\
\hline 1,2,4-trimethylbenzene & $7,8^{\mathrm{g}}$ & n.m. & n.m. & n.m. & n.m. & n.m. & n.m. & n.m. & $1,9^{\mathrm{h}}-2,8^{\mathrm{h}}$ & n.m. \\
\hline o-xylene & $5,2^{\mathrm{g}}$ & $5-8$ & n.m. & n.m. & n.m. & n.m. & n.m. & n.m. & n.m. & n.m. \\
\hline toluene & $5,0^{\mathrm{g}}$ & $25-58$ & $10^{\mathrm{h}}-19^{\mathrm{h}}$ & 84 & $19^{\mathrm{i}}$ & n.m. & $9^{\mathrm{g}}-38,8^{\mathrm{g}}$ & n.m. & $131,8^{\mathrm{h}}-305,5^{\mathrm{h}}$ & 182 \\
\hline $\mathrm{m}+\mathrm{p}$-xylene & $4,5^{\mathrm{g}}$ & n.m. & n.m. & $<30$ & n.m. & n.m. & $4,3^{g}-16,9^{g}$ & n.m. & n.m. & n.m. \\
\hline ethylbenzene & $1,8^{\mathrm{g}}$ & n.m. & n.m. & 12 & n.m. & n.m. & n.m. & n.m. & $8,4^{\mathrm{h}}-46,1^{\mathrm{h}}$ & 26 \\
\hline acrolein & $1,4^{\mathrm{g}}$ & 3 & n.m. & n.m. & n.m. & n.m. & n.m. & n.m. & n.m. & n.m. \\
\hline styrene & $1,1^{\mathrm{g}}$ & n.m. & n.m. & n.m. & n.m. & n.m. & $3,8^{\mathrm{g}}-11,1^{\mathrm{g}}$ & $3^{\mathrm{h}}$ & $6,7^{\mathrm{h}}-10,2^{\mathrm{h}}$ & 32 \\
\hline benzene & $1,1^{\mathrm{g}}$ & 4 & $5^{\mathrm{h}}-27^{\mathrm{h}}$ & $<35$ & n.m. & n.m. & n.m. & n.m. & $0,3^{\mathrm{h}}-2,5^{\mathrm{h}}$ & 13 \\
\hline
\end{tabular}

${ }^{\mathrm{a}} \mathrm{SDH}:$ single detached house

${ }^{\mathrm{b}}$ APA : apartment

${ }^{c}$ EE: efficiency in energy

${ }^{\mathrm{d}}$ LE : built with low emitting material

${ }^{\mathrm{e}}$ TVOC measured by a photoionization Detector's

${ }^{\mathrm{f}}$ TVOC calculated from the total integrated signal between hexane and hexadecane

g geometric mean concentration

h mean concentration

i median concentration 
Table 8 - Comparison of the mean concentration of TVOC and geometric mean concentrations of the most frequently VOC and aldehydes quantified in this study in six occupied houses (A, B, C, D, E and F) in summer and winter with the results of previous studies conducted in newly occupied and ventilated dwellings less than one year old. Some of these houses may have been energy-efficient and/or built with low-emissions material. n.m.: not measured

\begin{tabular}{|c|c|c|c|c|c|c|c|c|c|}
\hline \multirow[b]{2}{*}{ Number and type of buildings } & \multirow{2}{*}{$\begin{array}{c}\text { Our study } \\
6 \mathrm{SDH}^{\mathrm{a}}\end{array}$} & \multirow{2}{*}{$\frac{[10]}{2 \mathrm{APA}^{\mathrm{b}}}$} & \multirow{2}{*}{$\begin{array}{c}{[36]} \\
24 \mathrm{SDH}^{\mathrm{a}}\end{array}$} & \multicolumn{2}{|c|}{ [11] } & \multirow{2}{*}{$\begin{array}{c}\text { [35] } \\
219 \mathrm{SDH}^{\mathrm{a}} \\
66 \mathrm{APA}^{\mathrm{b}} \\
7 \text { others }\end{array}$} & \multirow{2}{*}{$\frac{[30]}{6 \mathrm{APA}^{\mathrm{b}}}$} & \multicolumn{2}{|c|}{ [37] } \\
\hline & & & & $1 \mathrm{SDH}^{\mathrm{a}}$ & $1 \mathrm{SDH}^{\mathrm{a}}$ & & & $1 \mathrm{SDH}^{\mathrm{a}}$ & $1 \mathrm{APA}^{\prime}$ \\
\hline Characteristic of buildings & $\begin{array}{c}\mathrm{EE}^{\mathrm{c}} \\
\mathrm{LE}^{\mathrm{d}} \text { for five } \\
\end{array}$ & $\mathrm{EE}^{\mathrm{c}}$ and $\mathrm{LE}^{\mathrm{d}}$ & $E E^{c}$ & $E E^{c}$ & $\mathrm{EE}^{\mathrm{c}}$ & n.m. & n.m. & n.m. & n.m. \\
\hline TVOC & $130^{\mathrm{eg}}$ & {$\left[235^{\mathrm{f}}-1011^{\mathrm{f}}\right]$} & 388 & n.m. & n.m. & $328^{\mathrm{f}}$ & $153^{\mathrm{fg}}$ & n.m. & n.m. \\
\hline n-decane & $14.7^{\mathrm{h}}$ & n.m. & n.m. & {$[2.5-11.5]$} & {$[3.7-13.1]$} & $35^{\mathrm{g}}$ & n.m. & n.m. & 46 \\
\hline n-undecane & $16.0^{\mathrm{h}}$ & n.m. & n.m. & {$[5.5-10.8]$} & {$[3.3-11.7]$} & n.m. & n.m. & 409 & 64 \\
\hline benzene & $1.9^{\mathrm{h}}$ & {$[1-8]$} & n.m. & {$[0-27.1]$} & {$[1.8-25.4]$} & n.m. & n.m. & 30 & 3 \\
\hline ethylbenzene & $3.6^{\mathrm{h}}$ & n.m. & n.m. & n.m. & n.m. & $20^{\mathrm{g}}$ & n.m. & 11 & 18 \\
\hline styrene & $2.0^{\mathrm{h}}$ & n.m. & n.m. & n.m. & n.m. & $64^{\mathrm{g}}$ & n.m. & 6 & 3 \\
\hline toluene & $9.0^{\mathrm{h}}$ & {$[19-88]$} & n.m. & [8.6-35.3] & [11-41.6] & $27^{\mathrm{g}}$ & $12^{\mathrm{g}}$ & 464 & 159 \\
\hline $\mathrm{m}+\mathrm{p}$-xylene & $8.8^{\mathrm{h}}$ & n.m. & n.m. & {$[2.2-12.7]$} & {$[3.2-13.9]$} & n.m. & n.m. & 13 & 28 \\
\hline o-xylene & $4.5^{\mathrm{h}}$ & {$[2-7]$} & n.m. & {$[2.4-5.4]$} & {$[1.5-6.3]$} & n.m. & n.m. & 7 & 19 \\
\hline isovaleraldehyde & $5.5^{\mathrm{h}}$ & {$[0-7]$} & n.m. & n.m. & n.m. & n.m. & n.m. & n.m. & n.m. \\
\hline acetaldehyde & $16.5^{\mathrm{h}}$ & {$[10-21]$} & n.m. & [40.6-68.6] & {$[18.3-55.8]$} & n.m. & $12^{\mathrm{g}}$ & n.m. & n.m. \\
\hline formaldehyde & $22.8^{\mathrm{h}}$ & {$[21-45]$} & $33^{\mathrm{g}}$ & [20.3-39.3] & [24.9-49.6] & $134^{\mathrm{g}}$ & $13^{\mathrm{g}}$ & n.m. & n.m. \\
\hline hexaldehyde & $61.2^{\mathrm{h}}$ & {$[0-19]$} & n.m. & [166-289] & [94.3-201] & $5^{\mathrm{g}}$ & n.m. & n.m. & n.m. \\
\hline alpha-pinene & $12.2^{\mathrm{h}}$ & {$[1-34]$} & n.m. & [52.4-100] & [17.8-48.6] & $269^{\mathrm{g}}$ & n.m. & 475 & 152 \\
\hline limonene & $8.3^{\mathrm{h}}$ & n.m. & n.m. & [19.8-112] & {$[13.7-58.6]$} & $35^{\mathrm{g}}$ & $23^{\mathrm{g}}$ & 127 & 23 \\
\hline
\end{tabular}

${ }^{\mathrm{a}} \mathrm{SDH}$ : single detached house

${ }^{\mathrm{b}}$ APA : apartment

${ }^{c}$ EE: efficiency in energy

${ }^{\mathrm{d}} \mathrm{LE}$ : built with low emitting material

${ }^{\mathrm{e}}$ TVOC measured by a photoionization Detector's

${ }^{\mathrm{f}}$ TVOC calculated from the total integrated signal between hexane and hexadecane

g mean concentration

h geometric mean concentration 


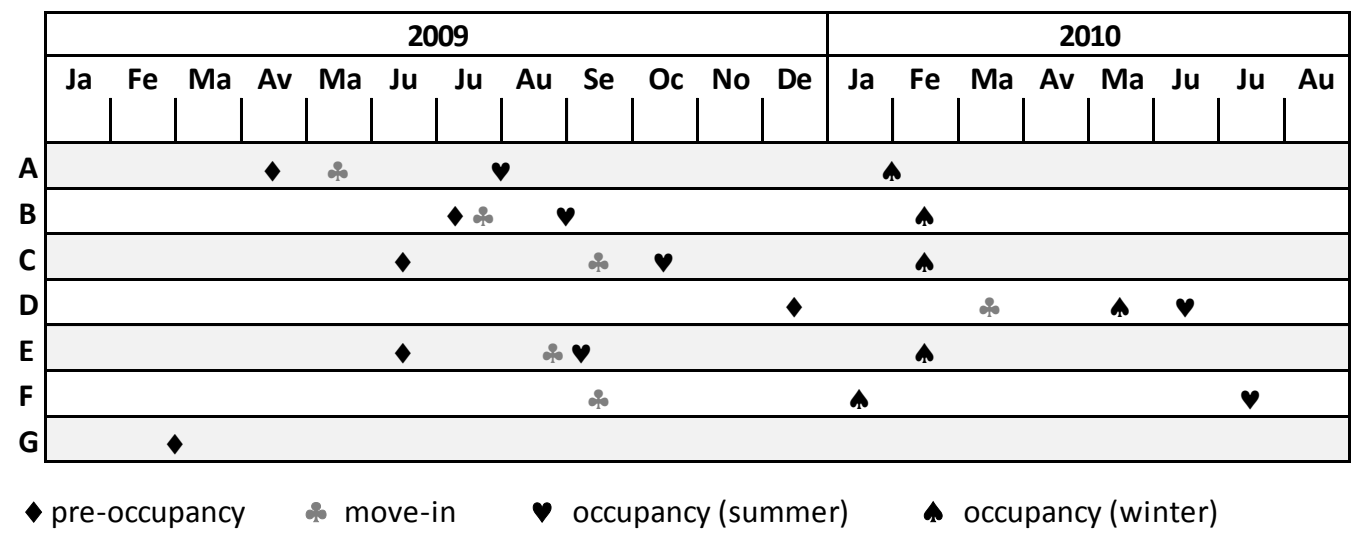

Figure 1 - Weekly investigation and moving dates of the seven new single-family detached houses between February 2009 and July 2010 

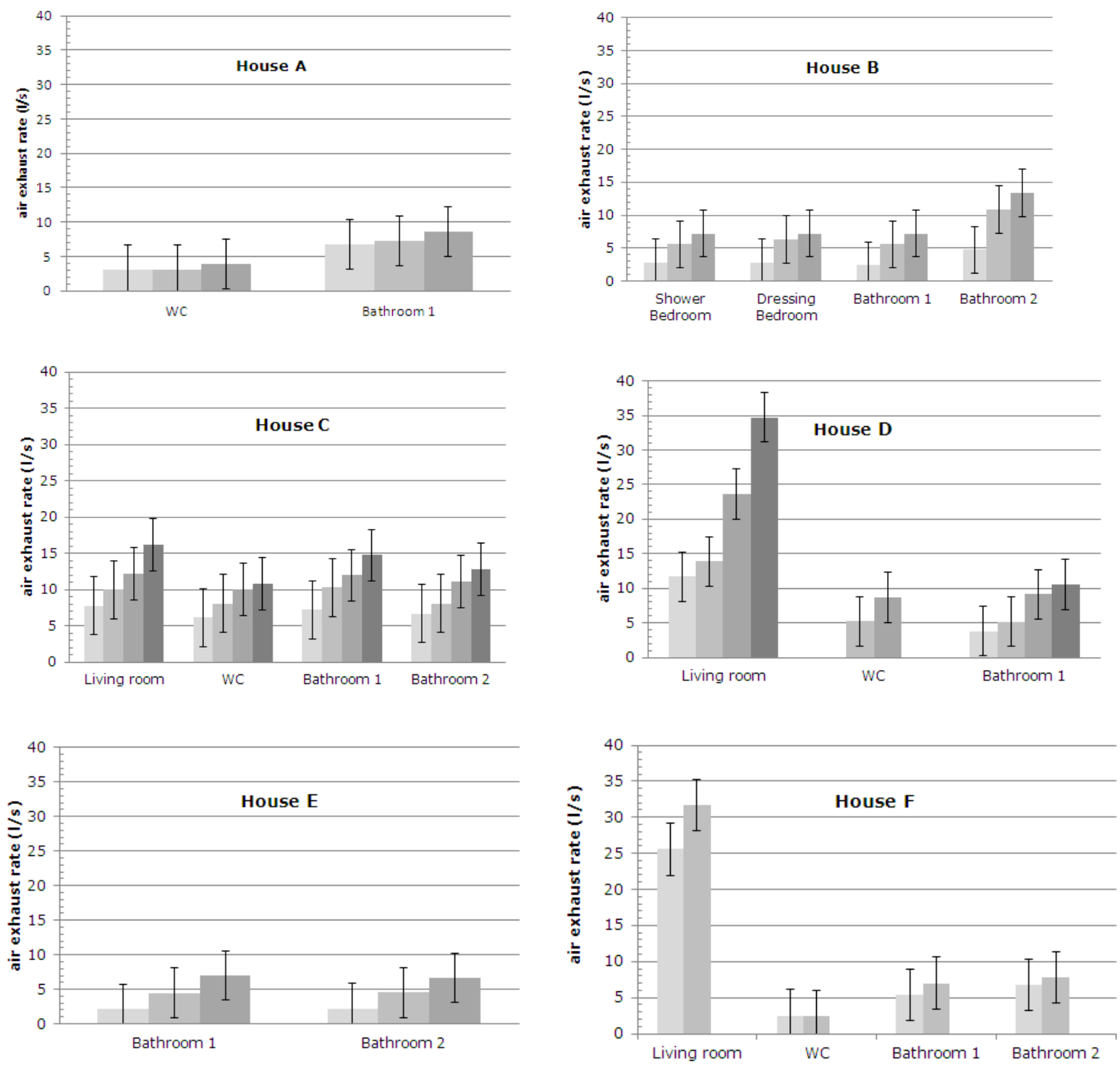

Fan speed setting of the MVHR : $\quad$ low (normal for F) $\square$ medium (or boost for F) wigh (boost for A) $\square$ very high

Figure 2 - Measured air exhaust rate (1/s) per room by the fan speed of the MVHR system in six houses 

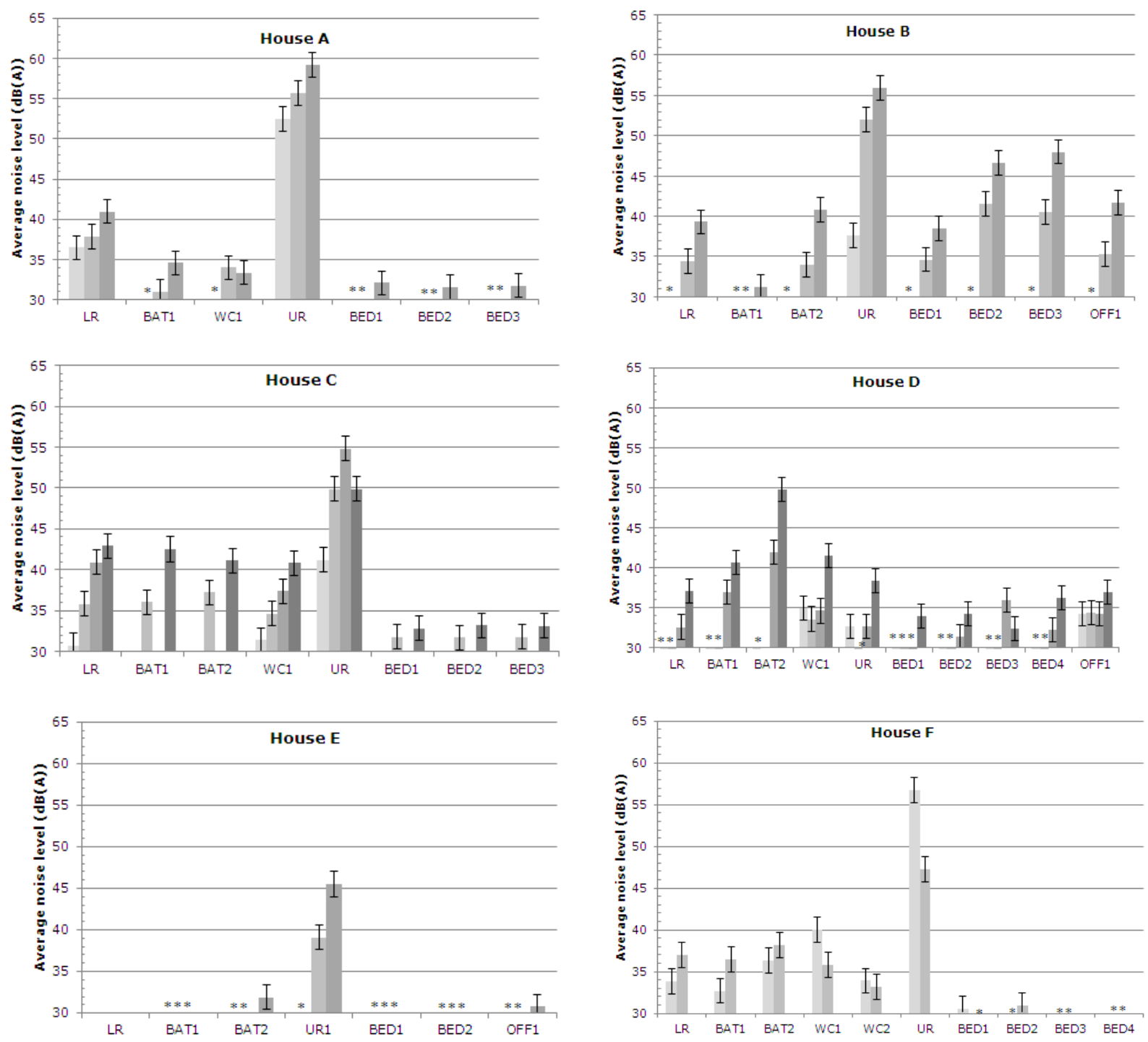

Fan speed setting of the MVHR: $\quad$ low (normal for F) $\square$ medium (or boost for F) ahigh (boost for A) $\square$ very high

Figure 3 - Measured average noise level $(\mathrm{dB}(\mathrm{A}))$ per room depending on the MVHR fan speed in six houses (* average noise level value $\leq 30 \mathrm{~dB}(\mathrm{~A})$ ) (BAT: bathroom; BED: bedroom; LR: living room; OFF: office room; UR: Utility room) 
$\square$ Pre $\square$ Sum $\square$ Win

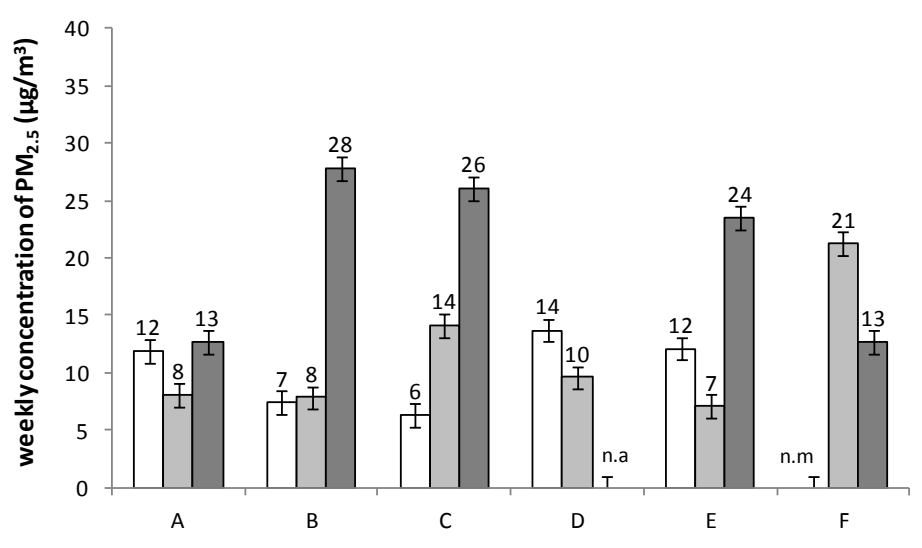

Figure 4 - Weekly mass concentrations of $\mathrm{PM}_{2.5}\left(\mu \mathrm{g} / \mathrm{m}^{3}\right)$ measured in the living room for six houses during the pre-occupancy stage (Pre) and during occupancy (summer: Sum; winter: Win). n.a.: not available; n.m.: not measured

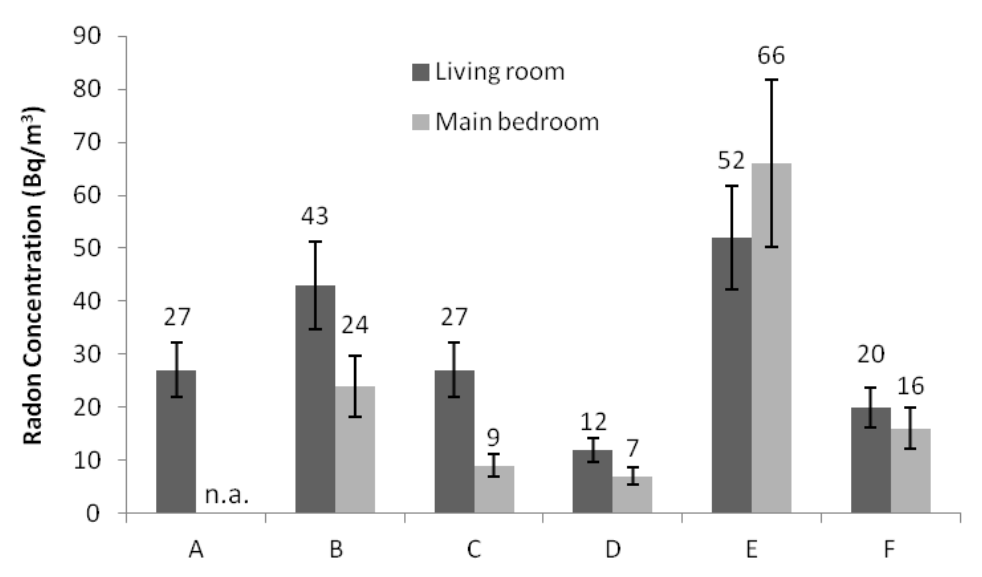

Figure 5 - Radon concentrations $\left(\mathrm{Bq} / \mathrm{m}^{3}\right)$ measured in the living room and in the main bedroom for six occupied houses. n.a.: not available 

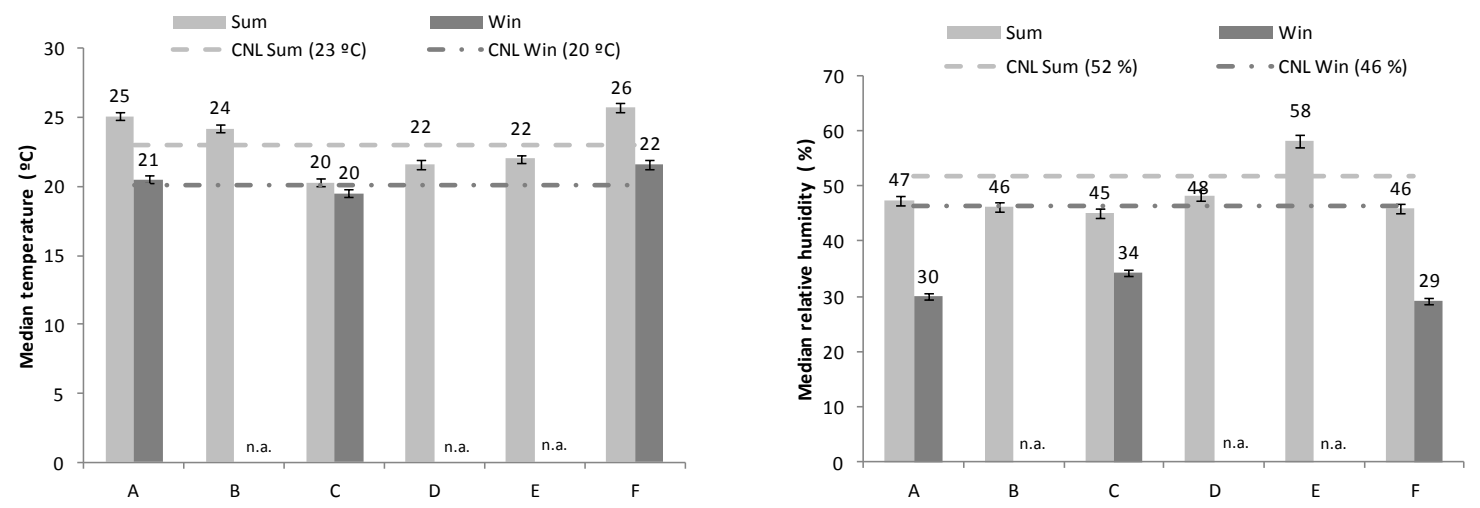

Figure 6 - Comparison of weekly median $\mathrm{T}\left({ }^{\circ} \mathrm{C}\right)$ and $\mathrm{RH}(\%)$ measured in the bedroom for six occupied houses (Sum: summer; Win: winter) to the seasonal values measured in standard French dwellings (CNL). n.a.: not available

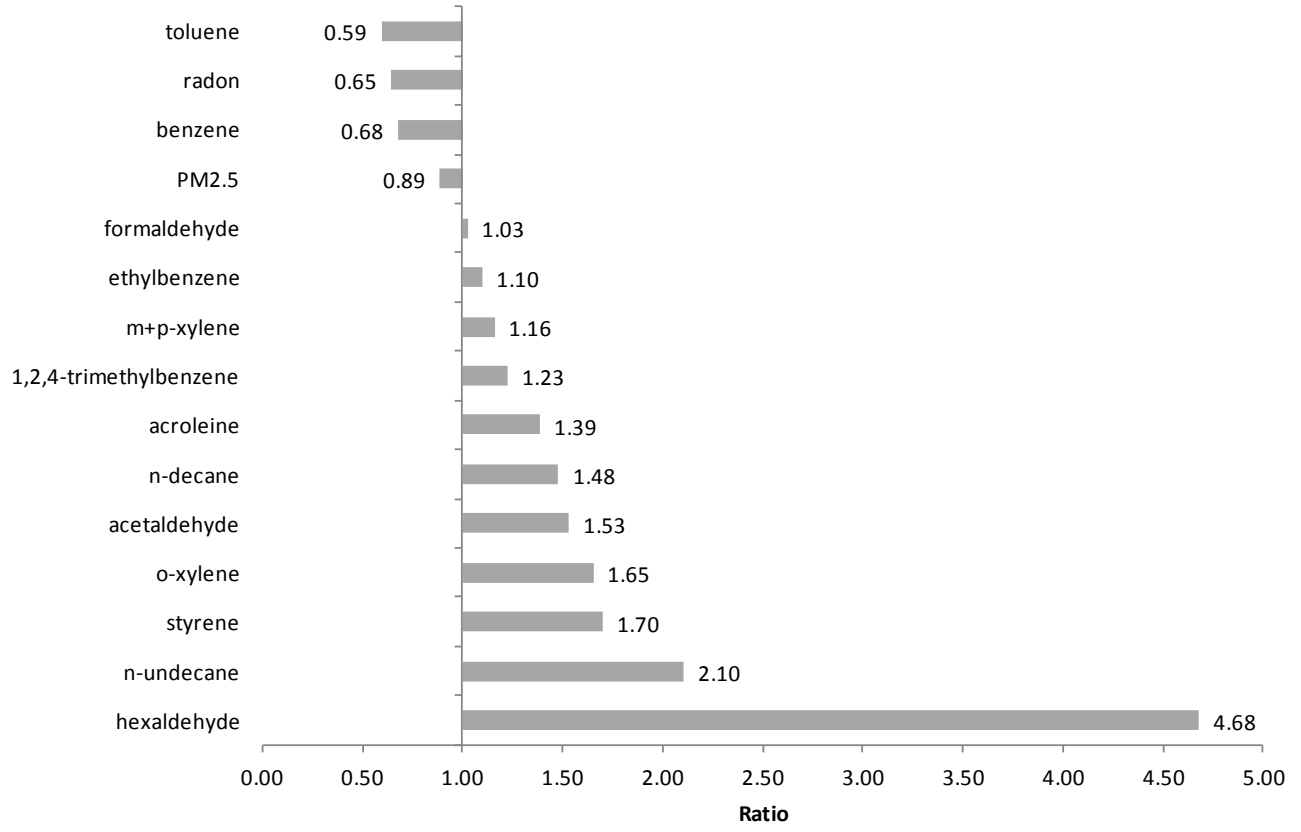

Figure 7 - Median ratio of the average concentrations of VOC, aldehydes, $\mathrm{PM}_{2.5}$ and radon measured in six occupied houses to the national median concentration in French dwellings 


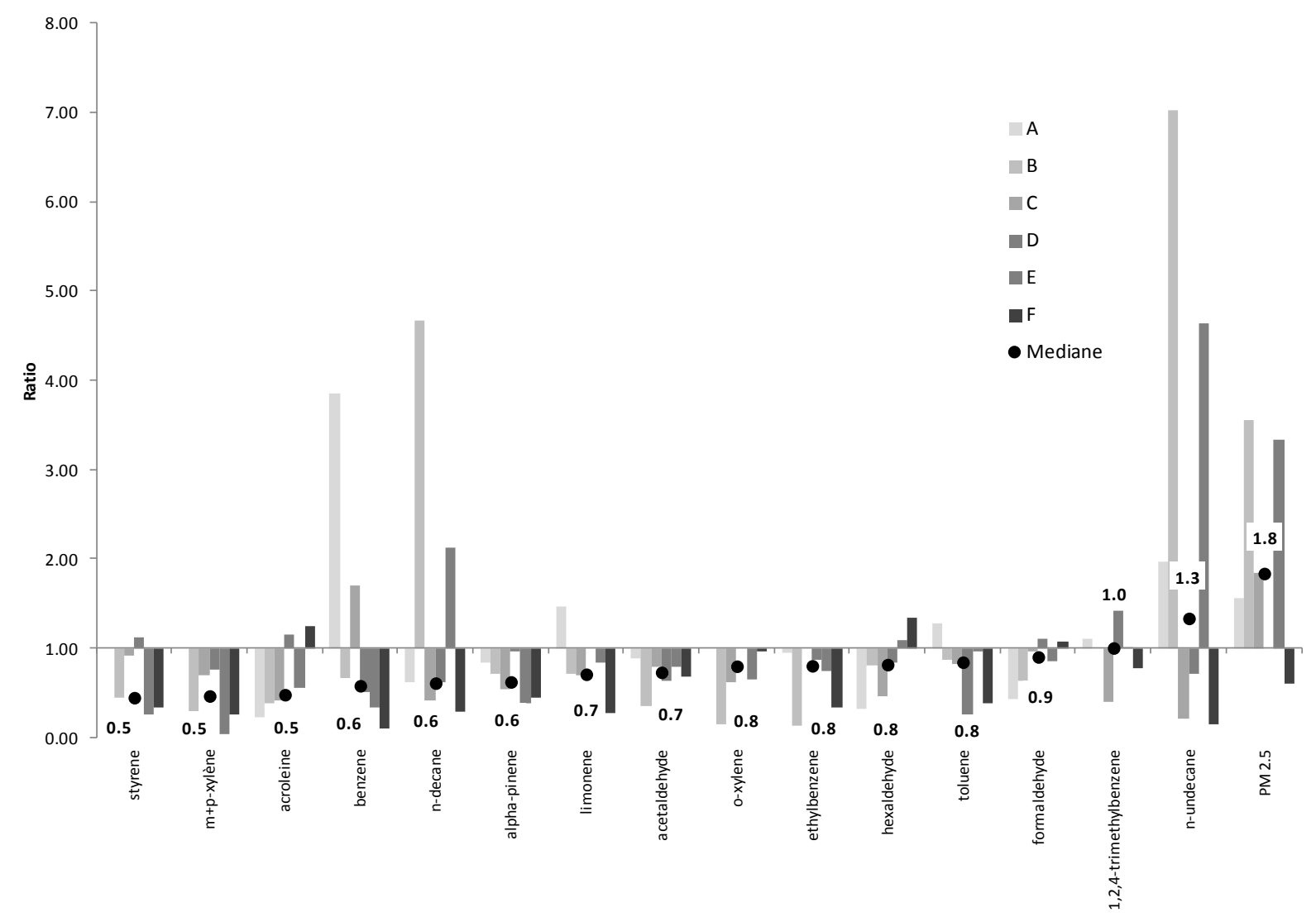

Figure 8 - Ratio of the concentrations of VOC, aldehydes and $\mathrm{PM}_{2.5}$ measured during the second survey to those measured during the first survey for each of six occupied houses and ratio of the median concentrations for all houses 